\title{
Hormone signaling pathways as treatment targets in renal cell cancer (Review)
}

\author{
ANNA M. CZARNECKA ${ }^{1}$, MAGDALENA NIEDZWIEDZKA ${ }^{1,2}$, CAMILLO PORTA $^{3}$ and CEZARY SZCZYLIK ${ }^{1}$ \\ ${ }^{1}$ Department of Oncology, Military Institute of Medicine, Warsaw; ${ }^{2}$ Faculty of Medicine, Medical University of \\ Warsaw, Warsaw, Poland; ${ }^{3}$ Medical Oncology, IRCCS San Matteo University Hospital Foundation, Pavia, Italy
}

Received January 4, 2016; Accepted February 14, 2016

DOI: $10.3892 /$ ijo.2016.3460

\begin{abstract}
Epidemiological, clinical, biochemical and genetic research has revealed that renal cell cancer (RCC) etiology is hormone-related. It was shown that hormone receptors are abnormally expressed in RCC cells. Abnormal endocrine stimulation also plays a significant role in RCC pathophysiology. Cellular proliferation, migration, angiogenesis, and drug resistance in $\mathrm{RCC}$ is modulated by para- and autocrine hormonal stimulation. In particular, RCC overexpression of gonadotropin-releasing hormone and its receptor was reported. On the contrary, corticotropin releasing hormone was reported to inhibit RCC cell proliferation and regulate angiogenesis. Overexpression of luteinizing hormone also promotes RCC tumor angiogenesis. Estrogen receptor $\alpha$ overexpression increases the transcriptional factor activity of hypoxia inducible factor HIF-1 $\alpha$, but estrogen receptor $\beta$ has a cancer suppressive role. Glucocorticoid receptors and androgen receptor are markers of indolent RCC and assigned tumor suppressive activity. Proopiomelanocortin is upregulated in VHL-mutated renal cell carcinoma via Nur77 transcription factor signaling. In RCC, follicle-stimulating hormone receptor promotes angiogenesis and metastatic formation via VEGF release. Mineralocorticoid receptor overexpression promotes cell survival and increases RCC cell proliferation. Vitamin D receptor expression is downregulated or absent in RCC and differentiate subtypes of renal cell tumors. RAR- $\beta$ promotes tumorigenesis but retinoic acid receptor $\gamma$ expression correlates negatively with the TNM stage at diagnosis. Finally, progesterone receptor expression is negatively correlated with the cancer stage. Molecular data analysis revealed the possibility of renal cancer cell proliferation induction via hormone activated pathways. Inhibition of hormonal signaling may thus play a putative role in supportive therapies against this cancer type.
\end{abstract}

Correspondence to: Dr Anna M. Czarnecka, Laboratory of Molecular Oncology, Department of Oncology, Military Institute of Medicine, Szaserow 128, 04-141 Warsaw, Poland

E-mail: anna.czarnecka@gmail.com

Key words: renal cancer, clear cell cancer, estrogen, vitamin D receptor

\section{Contents}

1. Introduction

2. Hypothalamus hormones

3. Pituitary gland hormones

4. Adrenal hormones

5. Sex hormones

6. Summary and conclusions

\section{Introduction}

Renal cell carcinomas ( $\mathrm{RCCs}$ ), tumors of epithelial origin, represent the majority of adult kidney neoplasms $(1,2)$. In $2015,61,560$ new cases were expected in USA (3.6\% of all new cancer) (3) and more than 10,380 in the UK. According to data in the Surveillance, Epidemiology, and End Results Registry, RCC is locally advanced in 53\% of cases, regionally advanced in $20 \%$ and metastatic in $22 \%$. Corresponding 5-year survival rates are 90, 61 and 10\%, respectively $(4,5)$. Due to RCC chemo- and radio-resistance and the limited number of available targeted therapies, overall response rates (ORR) and overall survival (OS) are still unsatisfactory $(6,7)$. Clear cell RCC (ccRCC) represents $85 \%$ of all renal cell cancers and arises from the proximal tubules. Both sporadic and inherited ccRCCs are associated with mutations in the von Hippel-Lindau (VHL) tumor suppressor gene. Mutation or inactivation (methylation) of the VHL gene with a subsequent second somatic event, often the deletion of the short arm of chromosome 3 (3p-), is associated with the development of ccRCC, and results in the deregulation of hypoxia-inducible pathways (8). The von Hippel-Lindau tumor suppressor protein (pVHL) acts as a HIF repressor by directly binding to hypoxia-inducible factor 1 -alpha $(\mathrm{HIF}-1 \alpha)$ and targeting it to the ubiquitin-dependent degradation pathway. Mutations of VHL result in constitutive stabilization of the HIF-1 $\alpha$ subunit, leading to highly angiogenic malignancy (9). This phenomenon occurs due to overexpression of vascular endothelial growth factor (VEGF), its receptors (VEGFR1, VEGFR2 and VEGFR3), and platelet-derived growth factor (PDGF) receptors in response to constitutive activation of HIF-1 $\alpha(10,11)$.

Some early clinical observations led to the hypothesis that RCC is a hormone-dependent tumor (12); these observations include the significant gender difference of RCC occurrence 
(twice as common in men as in women) $(12,13)$, a correlation between the cessation of gonadal activity and RCC development, and a reported regression of metastatic renal cancer during administration of progestin or androgen (occurring more often in men than in women). It was subsequently suggested that steroid receptor signaling pathways may become new targets for anticancer treatment. The efficacy of progesterone-based therapy, employed after nephrectomy, is supported by a large number of clinical observations. Primary reports seem to confirm that hormone treatment could be considered as a supportive treatment for metastatic RCC. Nevertheless, when RCC tumors are not hormone-dependent, as based on receptor expression, patients should only be treated with targeted therapy or immunotherapy, with or without radiotherapy $(12,14-16)$. Multiple endocrine factors related with ccRCC development and progression remain unidentified. The development of relevant tumor induction models is thus instrumental to proposing strategies for analyzing signaling pathways and verifying gene expression data.

The role of hormone-related factors in RCC etiology was first hypothesized over 20 years ago. Even today, epidemiological evidence is still more profound than molecular. In classic epidemiological studies, it was defined that, for women, ccRCC risk was inversely related to age at first given birth $(\mathrm{OR}=0.7$; for $\geq 25$ vs. $<25$ years), and that hysterectomies doubled ccRCC risk $(\mathrm{OR}=2.3)$. A negative association between ccRCC and age at menarche was also shown, suggesting a link between steroid sex hormones and ccRCC (17). Moreover, high parity was shown to be associated with an increased risk of ccRCC, while oral contraceptive use was associated with a reduced risk. Women with 5 or more births had a 2-fold increase in ccRCC risk when compared to those with 1 or 2 births (18). Some clinical studies concluded that due to significant gender differences, the occurrence of RCC will be twice as common in men as in women, for whom it will vary after the cessation of gonadal activity. These studies also showed that the majority of cases are diagnosed in adults aged 50-70 years $(12,13,19)$. At the same time clinical biochemical research revealed that serum levels of luteinizing hormones (LH), follicle-stimulating hormones (FSH), thyroid-stimulating hormones (TSH), luteotropic hormones (prolactin, PRL), human chorionic gonadotropin (beta-HCG) hormones, and parathyroid hormones (PTH) were significantly modulated in patients with urogenital tumors including RCC. After nephrectomy, PTH was frequently suppressed in these patients (20). Prolactin elevation was found in $45 \%$ of ccRCC patients regardless of the stage of the disease. At the same time, aberrant TSH and FSH were shown to be indicative of distant metastasis in ccRCC carriers. Serum PTH was also found to be decreased in patients with tumor dissemination. The overexpression of human gonadotropin-releasing hormone $(\mathrm{GnRH})$ and their receptors has been demonstrated in ccRCC (21). Inhibition of somatostatin (growth hormone-inhibiting hormone, or GHIH) release from the pituitary gland was also shown to control the proliferation of tumor cells through a family of $\mathrm{G}$ protein-coupled receptors [somatostatin receptor (SSTR)1-SSTR5] via the autocrine and paracrine modes. The indirect antitumor effects of SSTRs include anti-angiogenic actions $(22,23)$. Moreover, parathyroid hormone-related protein (PTHrP), a cytokine-like polyprotein, was determined to be a survival factor for human ccRCC: its expression was found to be negatively regulated by the VHL tumor suppressor gene at the level of messenger RNA (mRNA) stability (9), and induced phosphorylation of Akt at S473 via activated integrin-linked kinase (ILK), which in turn acted as either a phosphoinositide-dependent kinase (PDK2) or a facilitator protein to phosphorylate Akt, with nuclear factor kappa B (NF-kB) serving as the downstream Akt target (24). The examples mentioned above underscore the possibility of alternative pathway activation in ccRCC via hormones and illustrate the need to explore the molecular basis of phenomena observed in clinics $(25,26)$. Functional cell biology analysis has also recently provided new data. Most recently, a three-dimensional in vitro angiogenic system consisting of microvascular endothelial cells was used to study the influence of hormones on neovascularization and high levels of LH were found to promote angiogenesis in ovarian cancer models via the PI3K/AKT-mTOR pathway (27). Moreover, multiple clinical ccRCC research papers, on disease progression and treatment response, incorporate patient endocrine status in prognostic scores. The most notable current results indicate that hypothyroidism can serve as a predictive marker of therapy outcome in patients with metastatic RCC (28). In summary, ccRCC patients without paraneoplastic syndromes and no endocrinologic disease have frequent abnormalities in steroid and peptide hormones and expression of their receptors in renal cancer tumor masses, which in consequence influence disease progression $(29,30)$.

\section{Hypothalamus hormones}

Growth hormone-releasing hormone (GHRH). GHRH antagonists suppress the growth of ccRCC lines xenografted into nude mice. The antitumor effects of GHRH antagonists are exerted in part through the inhibition of the secretion of $\mathrm{GH}$ from the pituitary gland and the resultant reduction in levels of the hepatic insulin-like growth factor I (IGF-I). The main effects of GHRH antagonists are exerted directly on tumors, as the principal action of GHRH antagonists in vivo appears to be the direct suppression of autocrine and/or paracrine production and the expression of the genes encoding IGF-I (IGF1) and IGF-II (IGF2) in tumors (31). GHRH ligands are present in cancer cells and might function as autocrine and/or paracrine growth factors. Pituitary-type GHRH receptors and their splice variants are also found in tumor samples (32). The presence of the GHRH ligand has also been demonstrated in cancer cells, suggesting that GHRH could be a growth factor in RCC (31). GHRH antagonists JV-1-38 and MZ-4-71 inhibit the growth of orthotopic Caki-1 human RCC and inhibit the development of metastases in lung and lymph nodes $(31,33)$. The receptors for GHRH antagonists on Caki-1 tumors are distinct from binding sites detected in the pituitary gland (34). More recently in ACHN, A498 and 786-0 human RCC cells GHRH antagonists MIA-602, MIA-604, MIA-606 and MIA-690 inhibited the proliferation of these cells in nude mouse xenograft models (35). More data are still needed.

Somatostatin (growth hormone-inhibiting hormone-SS, GHIH or SRIF). The presence of transcripts for somatostatin receptor (SSTR) subtypes 1, 2, 3 and 4 was proven in RCC tissues (36) and human proximal tubular epithelial cells (PTEC). PTECs 


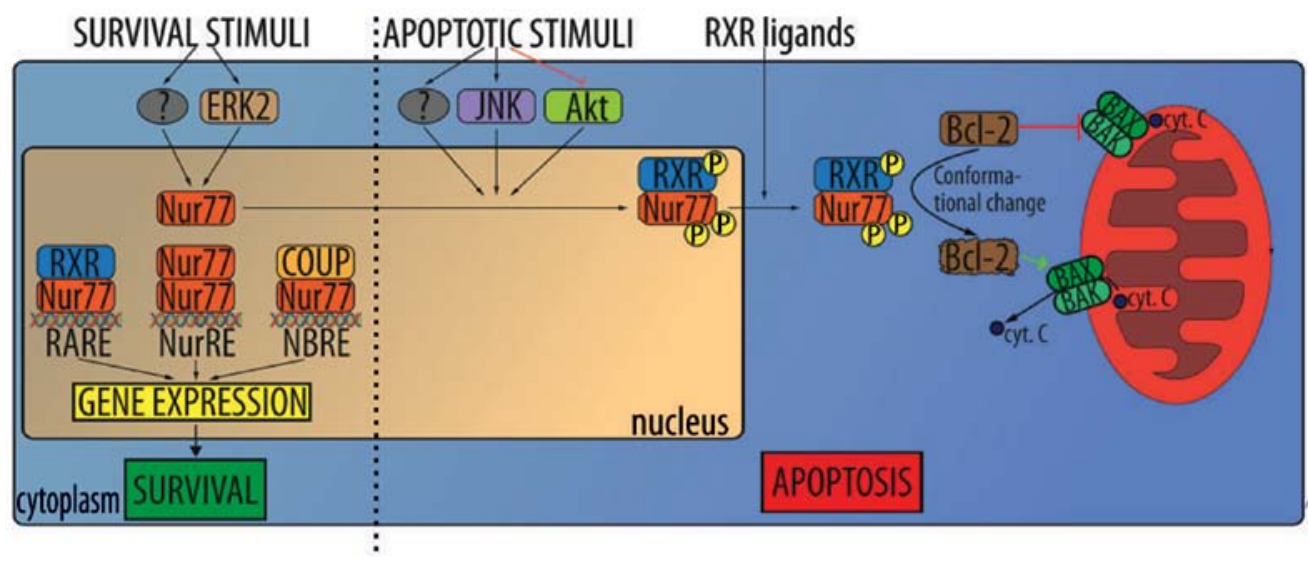

Figure 1. Nur77 signaling pathway in RCC cells.

express somatostatin, but mitogens, epidermal growth factors (EGFs), and hydrocortisone inhibit PTEC somatostatin secretion; however, direct stimulation by adenylate cyclase (i.e. forskolin) and fetal bovine serum induce secretion of somatostatin in PTEC cell cultures. These findings raise the possibility that renal-derived somatostatin modulates tubular cell function via autocrine and paracrine mechanisms (37). Nevertheless, phase II trials of somatostatin analogue administration (SSA) did not result in the control of RCC growth. Consequently, the use of SSA in advanced RCC does not seem to be a relevant therapeutic option (38); therefore, the role of $\mathrm{SS}$ in ccRCC requires further elucidation.

Corticotropin-releasing hormone (corticotropin-releasing factor, corticoliberin $\mathrm{CRH}$ or $\mathrm{CRF}$ ). Corticotropin-releasing hormone (CRF) acts via signaling mediated by corticotropinreleasing hormone receptors (CRHRs). The effects of Urocortin (Ucn) are also exerted through the activation of CRFRs and the involvement of the Ucn-CRFR system in pathophysiological conditions, including the regulation of angiogenesis and the inhibition of its proliferation was described in RCC. Suppression of neovascularization through VEGF reduction and tumor cell cycling inhibition is modulated mainly through the activation of CRHR2 (39). The direct activity of corticotropin-releasing hormones on ccRCC cells was only described recently. Corticotropin-releasing hormone-binding protein (CRHBP) gene downregulation is 33-fold on mRNA level in RCC tissues compared to control paired normal tissues. This CRHBP downregulation is also correlated with aggressiveness of RCC tumors (40).

Thyrotropin-releasing hormone (prolactin-releasing Hormone-TRH, TRF or PRH). Thyrotropin-releasing hormone [stimulates the release of thyrotropin (thyroid-stimulating hormone, TSH)] and prolactin from the anterior pituitary, but may also be taken up by kidney cells (41). Specific DNA hypermethylation of $\mathrm{CpG}$ sites on TRH gene was only reported over last years in RCC (42), and no further clinically relevant data is available at this time.

Gonadotropin-releasing hormone (Luteinizing hormonereleasing hormone-GnRH or $\mathrm{LHRH}$ ). Gonadotropin-releasing hormone (GnRH), also known as follicle-stimulating hormone- releasing hormone (FSH-RH), luteinizing hormone-releasing hormone (LHRH), gonadoliberin, and luliberin mediates release of follicle-stimulating hormone (FSH) and luteinizing hormone $(\mathrm{LH})$ from the anterior pituitary but expression of LHRH receptors was investigated in surgically removed specimens of RCC and in human RCC cell lines (A-498, ACHN and 786-0), and positive staining (expression) was found in each of the cases. In the tumor samples, LHRH receptor expression was found to be very high. It was therefore hypothesized that inhibitors of LHRH receptors (i.e. AN-201 or AEZS-108), which bind with high affinity to LHRH receptors, can be targeted against ccRCC tumors with overexpression of these receptors $(43,44)$. In Caki-1 cell line-based xenograft models, GnRH antagonists [i.e. Cetrorelix (SB-75)] were tested and shown to effectively inhibit the growth of RCC tumors. It was subsequently proposed that this group of compounds should be considered in therapies for patients with metastatic ccRCC (45). The whole genome gene expression profile of LHRH-activated ccRCC cells is not currently known.

Proopiomelanocortin (POMC). It was shown that proopiomelanocortin (POMC), an adrenocorticotropic hormone precursor, is upregulated in VHL-mutated RCC. Regulatory mechanism in which proopiomelanocortin (POMC) and nuclear receptor subfamily 4 group A member 1 (NR4A1)/ Nur77 are upregulated in VHL-mutated RCC was identified. Nur77, a member of the orphan steroid receptor superfamily, is believed to be activated by HIF under hypoxic conditions, and in turn regulate the production of the peptide hormone precursor POMC (46). Nur77 was identified as a critical transcription factor responsible for POMC overproduction and to be directly regulated by HIF. HIF-1 $\alpha$ (but not HIF- $2 \alpha$ ) binds to a HIF-responsive site in the Nur77 promoter region, activating the expression of Nur77 during hypoxic (VHL-mutant) conditions. Mutation or deletion of the HIF binding site in the Nur77 promoter region significantly decreased activation of a Nur77 and its target genes. The treatment of cells with Nur77 antisense oligonucleotides reduces POMC transcription under hypoxic conditions. In contrast to the normal control tissue the tumor tissues produce abnormally high amounts of Nur77 and POMC. Taken together, these results strongly suggest that Nur77 is both necessary and sufficient for hypoxia-dependent transcription of POMC (Fig. 1) (46). 


\section{Pituitary gland hormones}

Growth hormone (human growth hormone, somatotropin$H G H, G H)$. Growth hormones (GH) stimulate proliferation and differentiation of normal human cells but have also been shown to be involved in the development of malignant tumors by leading to excess IGF-I production in the liver, as well as having direct effects via GH receptors (GHR) expressed in a variety of tumors, including RCC, colorectal and breast cancer $(12,47)$. Both GH and IGF-I have been shown to act as oncogenes by inducing mitogenic and anti-apoptotic effects in a variety of tumors and cancer-derived cell lines via endocrine and/or autocrine/paracrine mechanisms. It should be noted that the expression of IGF-IR is increased by the activation of oncogenes such as SV40 T antigen and c-MYB, but decreased by the activation of tumor suppressor genes such as p53 and WT1 (48). Oncogenic transformation seems to be responsible for the local expression of IGF-IR and GHR in tumor tissues including RCC. It has been reported that acromegaly patients have an increased risk of developing malignant tumors, although several epidemiological studies have shown that RCC rarely co-occurs with acromegaly (49). Several epidemiological and experimental studies have proposed the hypothesis that elevated GH/IGF-I levels are associated with oncogenic processes in RCC, thyroid tumors, and colon cancer, and play a crucial role in tumorigenesis in acromegaly and/or the growth in multiple tumors (50). Sekizawa et al (49) described a case in which a 56-year-old man diagnosed with acromegaly was also found to have multiple tumors (ccRCC, colon cancer, follicular thyroid tumor and GH-producing pituitary adenoma). This is a rare case, as the association of acromegaly with multiple tumors other than in MEN1 has not been reported elsewhere in the literature. Nevertheless several large-scale epidemiological studies on the co-incidence of neoplastic diseases and acromegaly have shown coincidence with RCC.

Adrenocorticotropic hormone (ACTH). The biosynthesis of adrenocorticotropic hormone (ACTH), also known as corticotropin is controlled by a multiple transcription factors through the promotion of proopiomelanocortin (POMC), the precursor to ACTH and other enzymes involved in the synthesis of steroid hormones in pituitary cells. Hypoxia activates the hypothalamic-pituitary-adrenal (HPA) axis, resulting in an increase of ACTH and ACTH receptor expression; this suggests that oxygen fluctuation may influence the release of cellular hormones in the tumor niche (46).

Thyroid-stimulating hormone (TSH). Patients with thyroid disease (TD) and abnormal TSH levels, including on-nodular TD, solitary nodules, multinodular TD, thyroid cancers [with either the presence or absence of anti-thyroglobulin $(\mathrm{TgAb})]$, and anti-thyroid peroxidase (TPOAb) or anti-thyroid-stimulating hormone (TSH) receptor autoantibodies, are at higher risk of developing kidney cancer $(\mathrm{OR}=3.40)$ compared to the general population (51). Whereas, hypothyroidism is associated with longer progression-free survival (PFS) in sunitinib and sorafenib treatments $(25,28)$. The severity of vascular endothelial growth factor receptor tyrosine kinase inhibitor (TKI) therapy-associated hypothyroidism (TSH >10 mIU/l) is associated with improved treatment efficacy and survival outcomes in patients with metastatic RCC (52). This year meta-analysis suggested that development of hypothyroidism during TKI therapy is not clearly predictive of efficacy in patients with metastatic RCC or advantage in overall survival (OS) (53).

Follicle-stimulating hormone (FSH). Follicle-stimulating hormones (FSHs) are released under the influence of gonadotropin-releasing hormones (GnRH). The FSH receptor (FSHR), which was expected to be expressed only in the ovary and testis, was recently detected in the blood vessels of many solid tumors, including RCC $(54,55)$. FSHR expression was evaluated in the endothelium of 1,336 primary solid tumors, representing 11 tumor types, comprised mostly of genitourinary malignancies and 64 RCC cases. The FSHR expression in the neo-vasculature of tumors found it almost exclusively in peripheries, in a region $<1 \mathrm{~cm}$ inside or outside of the tumor in $70 \%$ of cases, but $\sim 30 \%$ of samples had equal FSHR expression in total tumor mass. FSHR expression was not detected in the blood vessels of nonmalignant tissues $(55,56)$.

Based on functional studies it was suggested that FSHR may contribute to neoangiogenesis, which would make it an interesting target for therapeutic and imaging purposes, as well as a potentially useful prognostic and/or predictive biomarker in genitourinary cancers. FSHR may also contribute to the development of metastases due to its position on the luminal surface of the endothelium. Moreover, FSHR may play a role in tumor intravasation, allowing RCC cells to penetrate through the endothelium and into circulation (57). In addition, FSHR expression at the periphery of tumors (55), where the tumor interacts with the stroma, may suggest its role in metastases. The epithelial-to-mesenchymal transition (EMT) is believed to be critical to the formation of metastases, while the interaction of stromal elements with tumor cells at the tumor periphery is thought to contribute to EMT. FSHR has also been proposed as a marker of tumor endothelium in solid tumors (56). Expression of FSH receptor (FSHR) expression was shown to be effective prediction markers of tumor vasculature response to sunitinib treatment. The percentage of FSHR-stained vessels was on average 5 times higher for patients who responded to treatment than the control group, and almost 8 times higher than in the non-responsive group. However, no significant differences were detected in the total density of vessels between these 3 groups, nor was a significant correlation found between FSHR expression and tumor grade. Nevertheless, a far greater number of FSHR-positive vessels were detected in patients who responded to the treatment. The response threshold between the two groups of patients was defined at 23\% FSHR-positive vessels. Not only was a higher density of FSHR-expressing vessels observed in the primary tumors of patients who responded to sunitinib treatment, but the von Willebrand factor (vWF) was detected in these vessel $\left(\mathrm{FSHR}^{+} / \mathrm{vWF}^{+}\right)(30)$. Plausible mechanisms that could explain this correlation have been hypothesized. One possible mechanism is that FSHR stimulation by FSH leads to VEGF secretion by the ECs, which in turn stimulates VEGFR2 on the ECs as an autocrine mechanism. In fact, it has been observed that the binding of FSH to FSH receptors in ovarian granulosa cells induces an increase in hypoxia-inducible factor 


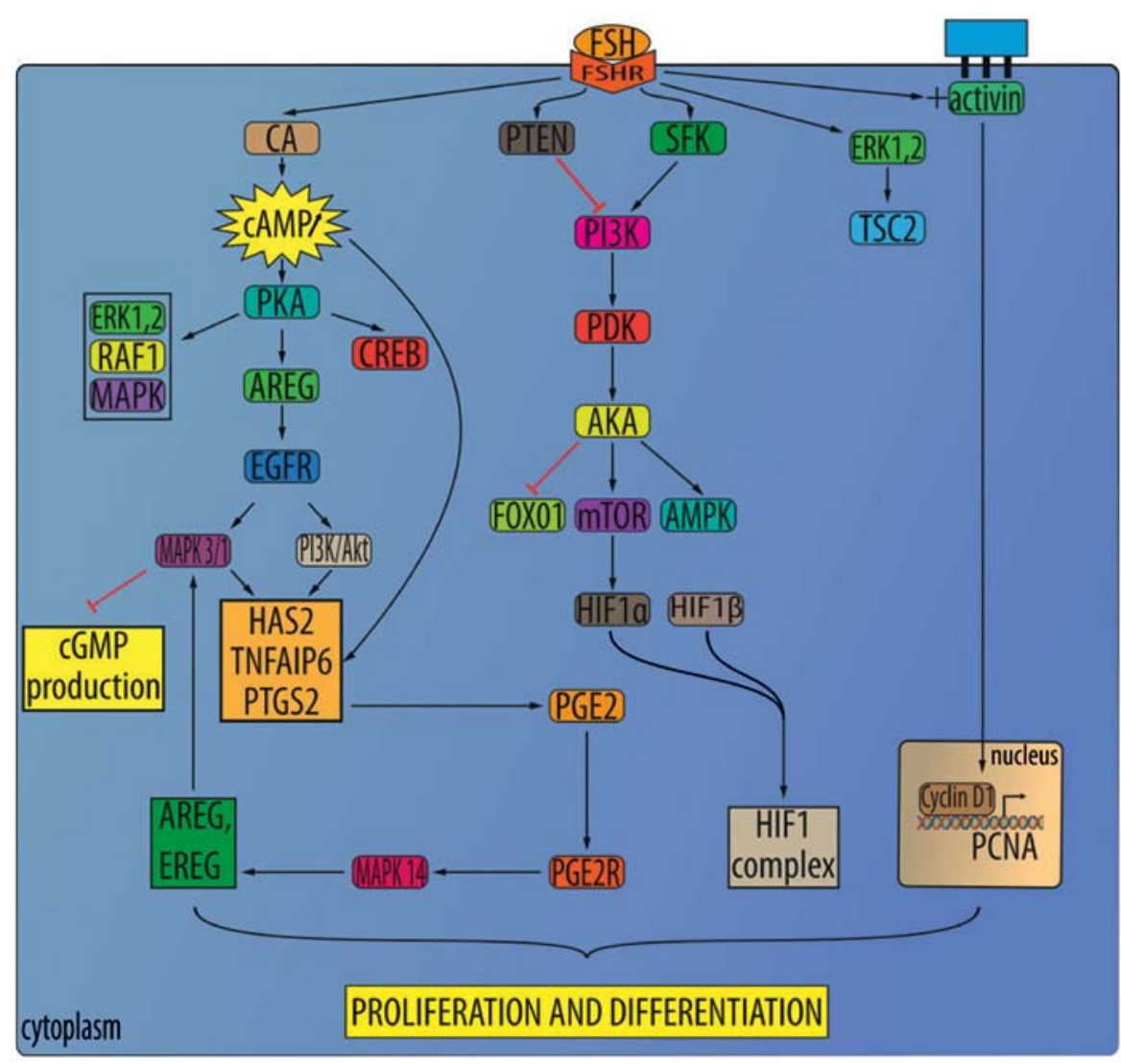

Figure 2. The effect of FSH stimulation on RCC cells.

$1 \alpha$ protein levels, which consequently leads to upregulation of VEGF production (Fig. 2) (57). It was later suggested that FSHR expression in the blood vessels of ccRCC primary tumors can be used to predict if patients will respond to sunitinib treatment (56). Another possible explanation for the correlation between FSHR expression and sunitinib efficacy is that FSHR activates one or more of the other kinases known to be inhibited by sunitinib like c-Kit, PDGFR, CSF-1R, FLT3 or RET (30).

Treatment. The FSH-FSHR signaling axis can be targeted with drugs in several ways, and GnRH antagonists that decrease FSH levels are currently available. Futhermore, the use of FSH-neutralizing antibodies could potentially cause an even greater reduction in FSH levels. FSHRs may be targeted by the use of molecules with drug- or radio-immunoconjugates. In order to do so, several classes of antagonizing compounds have been identified, most of which are negative allosteric modulators. An example is the thiazolidinone analogues, whose modifications in the chemical structure of the thiazolidinone backbone allow it to divide its generation into positive, mixed, and negative allosteric modulators of FSHR (30). Several studies have explored the use of FSHR allosteric modulators in vivo. Recently, ADX61623, another negative allosteric modulator of FSHR, was investigated. ADX61623 inhibited some elements of FSHR signaling, such as progesterone synthesis and cAMP production, but failed to inhibit estradiol synthesis (56). FSHR-antagonizing molecules need to be examined further, as they may play a role in targeting FSHR in RCC and other tumors.
Prolactin (PRL). Prolactin (PRL) is measured by its pathological range in patients with RCC. Even patients without paraneoplastic syndromes experience frequent changes that are directly caused by RCC (20), although only a single case of hyperprolactinemia induced by RCC has thus far been reported (58).

\section{Adrenal hormones}

Glucocorticoid receptors (GR). In normal kidneys, glucocorticoid receptors (GRs) are expressed in proximal tubules and glomeruli. In RCC, high GR expression is a positive prognostic marker. Initial studies, conducted in the early 1980s, and that discovered the presence of GRs in kidney tumors, were based on ligand-binding assays $(59,60)$. GRs were found to be overexpressed in $66 \%$ of ccRCC cases, $26 \%$ of pRCC cases, $14 \%$ of oncocytomas and $6 \%$ of chRCC cases. Moreover, GR expression serves as a favorable marker and correlates with low nuclear grade and stage. A significant correlation between GR expression and OS in RCC patients may be hypothesized. The majority of patients with ccRCC-expressing GRs were still alive by the end of the follow-up, in contrast to those with expression-negative tumors $(59,61)$. As a result, the correlation of GR expression with less aggressive tumor behavior was reported and the anti-proliferative role of GR signaling in RCC was suggested. Suppression of transcription factors, including cAMP response element-binding protein (CREBs), nuclear factor kappa-light-chain-enhancer of activated $\mathrm{B}$ cells (NF- $\kappa \mathrm{Bs}$ ), signal transduction activator of transcription (STATs), activator protein 1 (AP-1s), p53s, CCAAT-enhancer- 
binding proteins (C/EBP), and SMADs was suggested as inhibitory mechanisms mediated by GR signaling $(59,62)$. In RCC, two main isoforms of GR were analyzed. GR- $\alpha$, a predominant isoform, exhibits steroid binding activity. GR- $\beta$ has a lower expression in normal kidney tissues, but is overexpressed in inflammatory blood cells localized in the tumor (59). In RCC, GRs have been shown to bind not just glucocorticoids (63), but with progesterone, diethylstilbestrol, testosterone, and aldosterone as well, albeit with low affinity. In addition, progestin or medroxyprogesterone easily binds to GRs. As a result of medroxyprogesterone acetate treatment RCC tumor regression was reported (64).

Treatment. Efficacy of RU486 (Mifepristone), a glucocorticoid receptor antagonist, on TRAIL-induced apoptosis in human RCC, Caki-1, A498 and ACHN cell lines was measured. RU486 is known as an anti-progesterone and anti-glucocorticoid agent. Its low dose has no effect on apoptosis, but sensitizes Caki-1 cells to TRAIL-induced apoptosis. As a result, RU486 enhances TRAIL-mediated apoptosis through the downregulation of Bcl-2 and c-FLIP(L) as well as CHOP-mediated DR5 upregulation. TRAILs bind to their receptors (death receptors DR4 and DR5) to form death-inducing signal complexes (DISC) by recruiting caspase-8, which in turn increases apoptosis through the activation of caspase-3. In addition, TRAILs activate mitochondrial apoptotic pathways: TRAILs release cytochrome $c$ to the cytosol via disruption of mitochondria membrane permeability, allowing it to form apoptosomes. These responses were also commonly observed in a variety of other cancer cells, including SK-Hep-1 (hepatocarcinoma cells) and HT29 (colon cancer cells) (62). In addition, RU486 slightly inhibited XIAP expression, increased active cleaved caspase-3 and PARP cleavage, induced cytoplasmic histoneassociated DNA fragments, and blocked chromatin in the nuclei, indicating apoptosis. Moreover, RU486-mediated TRAIL-induced apoptosis acts independently of GR and PR signaling, through CHOP-mediated DR5 expression and the downregulation of Bcl-2 and c-FLIP expression. As TRAILs induce apoptosis only in tumor cells, they may be a promising cancer treatment, and medications such as RU486 may be a novel strategy for the recovery of TRAIL sensitivity in cancer cells otherwise resistant to TRAIL (62). In a study conducted by Arai et al (65), the inhibitory effects of dexamethasone (DEX) on the growth of RCC in vivo and in vitro were examined and suppression of NF- $\mathrm{B}$ activation was measured. DEX binds more powerfully to the glucocorticoid receptor than cortisol. DEX has long been used to suppress inflammatory reactions in patients with advanced cancers by activating transcription factor $\mathrm{NF}-\kappa \mathrm{B}$ and its target genes IL-6, IL-8 and VEGF. All the RCC cell lines tested responded to DEX treatment, but RCC growth suppression was more remarkable in vivo than in vitro. Caki-1 cells expressed a low level of GR protein, and GR was translocated into the nucleus. Moreover, after 6 weeks of treatment, mean tumor volume statistically decreased. H\&E staining showed less inflammatory cells and necrotic tissues in DEX groups as well. Intracellular IL-6, as well as those in the conditioned medium, was downregulated in all cell lines following treatment. Concentrations of IL-8 in the conditioned medium were remarkably decreased in NC65 cells, while VEGF secretion was lowered by $30-65 \%$ in all RCC lines, with the inhibition of the nuclear translocation of NF- $\kappa \mathrm{B}(65)$. After therapy with dexamethasone, cases of complete regression (CR) occurred, and the cases included patients with metastases located in the brain and lungs. Dexamethasone treatment may thus be a candidate for RCC supportive therapy. This compound was shown to inhibit expression and signaling mediated by NF- $\mathrm{B}$, VEGF, IL-6 and IL-8. Cortisone therapy was also reported to be successful in some cases. Over 10 years of complete remission (CR) was demonstrated in patients with retroperitoneal lymph node involvement and liver metastases. This observation supports the thesis that GR and its agonists may play an important role in anticancer ccRCC therapy (66). Using dexamethasone in combination with kinase inhibitors was examined (59).

Mineralocorticoid receptors (MR). Mineralocorticoid receptors (MR) in the kidneys are expressed in Henle's loop, distal tubules and collecting ducts. Due to its compartment-specific expression in the kidneys, MR was suggested as a diagnostic marker for oncocytomas and chromophobe RCC. MR was indicated as both a highly specific and sensitive marker of the distal nephron cells and its derived neoplasms (67). Aside from MR, 11beta-HSD2 [11 $\beta$-Hydroxysteroid dehydrogenase (HSD-11 $\beta$ or $11 \beta$-HSD)] was also investigated as a RCC subtype marker. Expression of both MR and 11beta-HSD2 was detected in the distal nephrons of normal kidneys. MR and 11beta-HSD2 were highly expressed in $90 \%$ of chromophobe RCCs and 93\% of oncocytomas, thus reflecting their histogenetic origin. No MR staining was detected in ccRCC, since its absence corresponds with its proximal tubule origin. Only $2.6 \%$ cases of ccRCC showed focal positivity for 11 betaHSD2, whereas all papillary RCCs were negative (67). In functional MR studies, aldosterone binding was observed to be more significantly decreased in clear cell RCCs than in normal tissues, both in the cytosol and in the nucleus (59).

Recent studies carried out in the US and Eastern Europe have shown that increased activity of the renin-angiotensinaldosterone system (RAAS) is one of the major risk factors influencing genetic changes and is mainly observed in cases of ccRCC. Epidemiological evidence suggests that RAASrelated hypertension and obesity increase the risk of RCC development (68), while epidemiological evidence from the MRC Blood Pressure Unit in Glasgow has shown that pharmacological suppression of the RAAS lowers the risk of developing renal cancer in hypertensive patients as opposed to their non-hypertensive counterparts. In experimental models, the inhibition of angiotensin-converting enzymes restricted the growth of human renal cancer cells in a mouse xenograft system; and in vitro, restored the sensitivity of mouse Renca cells to the growth-suppressing effects of TGF $\beta$. Moreover, in several experimental animal models of hypertension, overactivity of the RAAS was accompanied by renal tubular hyperplasia. One potential mechanism to explain this is the influence of the RAAS on the expression and activity of the K-ras cellular oncogene to promote tumor growth. King et al (68) also observed that the K-ras isoform K-RAS4A is aldosterone-sensitive in renal cancer, and that its overexpression contributes to the survival and increased proliferation of RCC cells in response to RAAS activation. This was demonstrated by adding spironolactone to RCC cultures, which 
blocked mineralocorticoid receptors and led to an absolute reduction in both cell number and K-ras expression. Thus, mineralocorticoid activation and K-RAS4A expression were shown to support RCC proliferation. A second study treatment involved transfection with siRNA, which also suppressed K-ras protein expression and decreased cell count by $\sim 40-73 \%$ after $72 \mathrm{~h}$. In addition, it was found that K-RAS4A acts through the Raf and Akt pathways to support the survival and growth of RCC cells. Both Raf and Akt proteins were markedly reduced following a decrease in K-RAS4A. According to Varela et al (69) there is evidence that K-ras may act in tandem with the SWI/SNF/PBRM1 complex to promote the formation of renal carcinoma. Kotelevtsev et al (70) demonstrated that the mineralocorticoid receptor is expressed in about half of human clear cell carcinomas. In this model, K-RAS4A expression was induced by aldosterone treatment and its activation sustained by an as yet unproven tyrosine kinase that may have been involved with the epidermal growth factor or insulin-like growth factor 2 receptor; also, K-RAS4A links the phosphatidylinositol 3-kinase pathway to ENaC activity. Thus, K-ras is also involved in cell growth promotion via aldosteronesensitive growth responses (70).

Vitamin D receptors (VDR). Vitamin D receptor (VDR) signaling regulates multiple target genes and promotes cell differentiation, angiogenesis, and angiogenic proliferation in multiple tissues, including the kidneys. Long-term vitamin D serum levels were suggested to be inversely correlated with renal cancer development risk. VDR was shown to be overexpressed in several malignant neoplasms, including metastatic RCC tumors, and in poorly differentiated and sarcomatous RCCs of Fuhrman grade IV in particular $(59,71)$. The relationship of 1,25-Dihydroxyvitamin D3 receptors (VDR) to histological features in RCC was further investigated (72). VDR expression was shown to be absent in the proximal tubules. In contrast, tumors originating from the distal nephron tested positive for VDR, including the majority of papillary RCCs, chromophobe RCCs and oncocytomas. Positive VDR staining could help in efforts to differentiate between papillary RCC and clear cell RCC with papillary features (73). VDR immunohistochemistry results can help classify RCC tumors (73). Generally, ccRCC tests negative for VDR. In addition, ccRCC exhibits decreased VDR mRNA levels when compared to normal kidney tissues, and VDR staining is limited only to the peripheral region of the tumor (73). Analysis of RCC samples exhibited expression of 1,25-dihydroxyvitamin D3 receptors in $81 \%$ of the tumors. Absence or loss of the receptor was associated with low differentiated sarcomatoid tumors with a poor prognosis. On the other hand, the expression of VDR receptors in the receptor-positive tumors did not correlate with clinical stage or pathological grade or RCC (72). The expression of $1,25-(\mathrm{OH})_{2} \mathrm{D}_{3}$ receptors was also analyzed in normal kidney tissues and primary RCC samples. In $83 \%$ of RCC cases, 1,25- $(\mathrm{OH})_{2} \mathrm{D}_{3}$ receptor expression was found, and in $65 \%$ of the cases the receptor was overexpressed. The mean expression of the $1,25-(\mathrm{OH})_{2} \mathrm{D}_{3}$ receptor in RCCs is significantly lower than in normal kidneys. The lower $1,25-(\mathrm{OH})_{2} \mathrm{D}_{3}$ receptor expression may be due to lack of differentiation in the malignant-transformed renal cells. A functional analysis of the $1,25-(\mathrm{OH})_{2} \mathrm{D}_{3}$ receptor in both normal and $\mathrm{RCC}$ tissues show similarities, which would suggest that the receptor may possess a normal cellular function in the transformed cells. A possible correlation between $1,25-(\mathrm{OH})_{2} \mathrm{D}_{3}$ receptor expression in primary tumors and the late development of lymph node metastases was also found (74). In an earlier study, no significant difference between expression of VDR in ccRCC and control tissues was found (75). Such a discrepancy could be explained by the variable degree of differentiation in the tumors analyzed in these two studies.

Subsequent physiological studies have revealed the complicated role vitamin D plays in renal tissue. According to several biochemical studies, even when exogenous vitamin D supplementation was present, the formation of VDR-DNA complexes in RCC was decreased. This impairment was shown to be secondary to deregulated VDR heterodimerization with RXR (retinoid $X$ receptor) in tumor cells. It was shown that the expression of RXR- $\gamma$ in RCC was correlated with OS of RCC patients (59). Another study discovered that VDR mRNA was almost undetectable in clear cell RCC as compared to normal kidney tissue, and was accompanied by the underexpression of CYP2R1, CYP27B1 and CYP27A1 enzymes (76). No correlation between concentrations of VDR receptors and cancer cell DNA-ploidy was found. The mean VDR concentration used was $8.4 \mathrm{fmol} / \mathrm{mg}$ of protein (range, 2.8-15.9) in diploid tumors and $7.0 \mathrm{fmol} / \mathrm{mg}$ of protein (range, 0-27.8) in DNA aneuploid tumors (11 out of 22) (74).

Treatment. Vitamin D exerts its anticancer activity by inducing apoptosis and inhibiting cell proliferation. This effect has been demonstrated in many cancer models, including malignant melanoma, breast cancer, osteogenic sarcoma and acute myelogenic leukemia (77). In one report, proliferation of the RCC cell line, derived from a pulmonary metastasis, was inhibited by calcitriol treatment (72). In another study, RCC tumor growth was inhibited, pulmonary and hepatic metastates were decreased, and the OS of mice was prolonged in relation to the dose of vitamin D provided (78). Although vitamin D-based supplementation therapy shows promising results, its implementation is impeded by its toxic hypercalcemic effect (59). Bypassing this toxicity is possible by using alternative vitamin D derivatives. At the same time, alkylating derivative 1,25-dihydroxyvitamin D3-3-bromoacetate was investigated in vitro and in vivo. This study showed that $1,25(\mathrm{OH})_{2} \mathrm{D}_{3}-3-\mathrm{BE}$ had a significantly more potent effect on the inhibition of human RCC cell line proliferation than an equivalent concentration of normal vitamin D. In addition, an increase in the apoptosis rate was observed with a reduction in cyclin A expression (79).

$R A R$ (retinoic acid) receptors and $R X R$ (retinoid $X)$ receptors. Expression of retinoic acid receptors (RARs) and retinoid $X$ receptors (RXRs) are cell type-specific. RAR and RXR are expressed in proximal tubules and renal interstitial cells. RAR- $\beta$ mRNA was found to be constrictively expressed in normal kidney cells. Furthermore, RAR and RXR expression was reported in podocytes (74). Expression of RXR- $\beta$ was reported in proximal tubules and interstitial cells, while RXR- $\alpha$ and RXR- $\gamma$ were present mostly in the nuclei of proximal tubule cells (80). In the analysis of 49 RCC tumors, RXR- $\alpha$ expression was detected in $70 \%$ of the cases, RXR- $\beta$ 
in $47 \%$ of the cases, and RXR- $\gamma$ in $85 \%$ of the cases (80). Only RXR- $\gamma$ expression was found to be inversely correlated with the TNM stage, because patients with RXR- $\gamma$-positive tumors were observed to have prolonged OS (59). RAR- $\beta$ probably contributes to tumorigenesis in RCC because the deletion of its gene on the short arm of chromosome 3 is frequently found in RCC and other cancers. RAR- $\beta$ mRNA is often not detectable in RCC cell lines. This also suggests minimal inhibition or resistance to 13-cis-RA treatment (59).

Treatment. In clinical studies, the effect of retinoic acid on RCC was tested in patients with multiple metastases. In a large trial, responses to therapy with either IFN- $\alpha 2 \mathrm{a}$ alone or in combination with 13-cis-retinoic acid (13-CRA) was evaluated. This study showed that $19 \%$ of patients on combined treatment did not show progression after 24 months. Progression-free (PFS) and overall survival (OS) rates for patients were significantly longer when treated with combined IFN- $\alpha$ 2a and 13-CRA therapy (81). In another study, 3 different treatment arms were analyzed: i) a treatment group given a combination of IFN- $\alpha 2 a$, IL-2, and fluorouracil; ii) a treatment given a combination of IFN- $\alpha 2 a$, IL-2, fluorouracil, and 13-CRA; and iii) a control group given vinblastine and IFN- $\alpha$. The results showed that group 1 and 2 had a significantly longer progression-free period and overall survival rate, although no significant difference in efficacy between them was demonstrated (82). According to both of the studies mentioned above, retinoid treatment can have a beneficial effect, at least for a subgroup of RCC patients.

\section{Sex hormones}

Estrogen receptors (ER). Two isoforms of estrogen receptors (ER) are known and are encoded on different chromosomes: ER- $\alpha$ and ER- $\beta$. ER- $\alpha$ is mainly expressed in reproductive organs, while ER- $\beta$ is expressed in genitourinary human tissues in the central nervous system. Both types of estrogen receptors are also expressed in normal renal interstitial stromal cells. In tumor samples, ERs are found in stromal tumors, cystic nephromas and angiomyolipomas (59). The relative concentrations of these receptors in the renal tumor is as follows: progesterone $>$ estrogen $>$ androgen $>$ glucocorticoid $>$ mineralocorticoid receptors (Fig. 3) (83). The affinity of the ER- $\beta$ isoform to bind with 17- $\beta$-estradiol is similar to ER- $\alpha$. At the same time, androgens and phytoestrogens are bound with greater affinity by ER- $\beta$ (84).

Clinical studies. Initial studies in estrogen and RCC covered the procedure for experimental induction of cancers. The procedure covers the supply of female sex hormones to male mice, or male Syrian hamsters, as well as in female guinea pigs, after ovariectomy, during low progesterone secretion, or before reproductive maturity. Endocrine balancing following the resection of ovaries has been seen to delay the occurrence of tumors in various organs, including the kidneys. Moreover, environmental exposure to both xeno-estrogen and estrogen is associated with cancer development. RCC can be experimentally induced in animal models by exposure to high levels of estrogen, which might suggest the involvement of estrogen receptors in the etiology of renal cancer

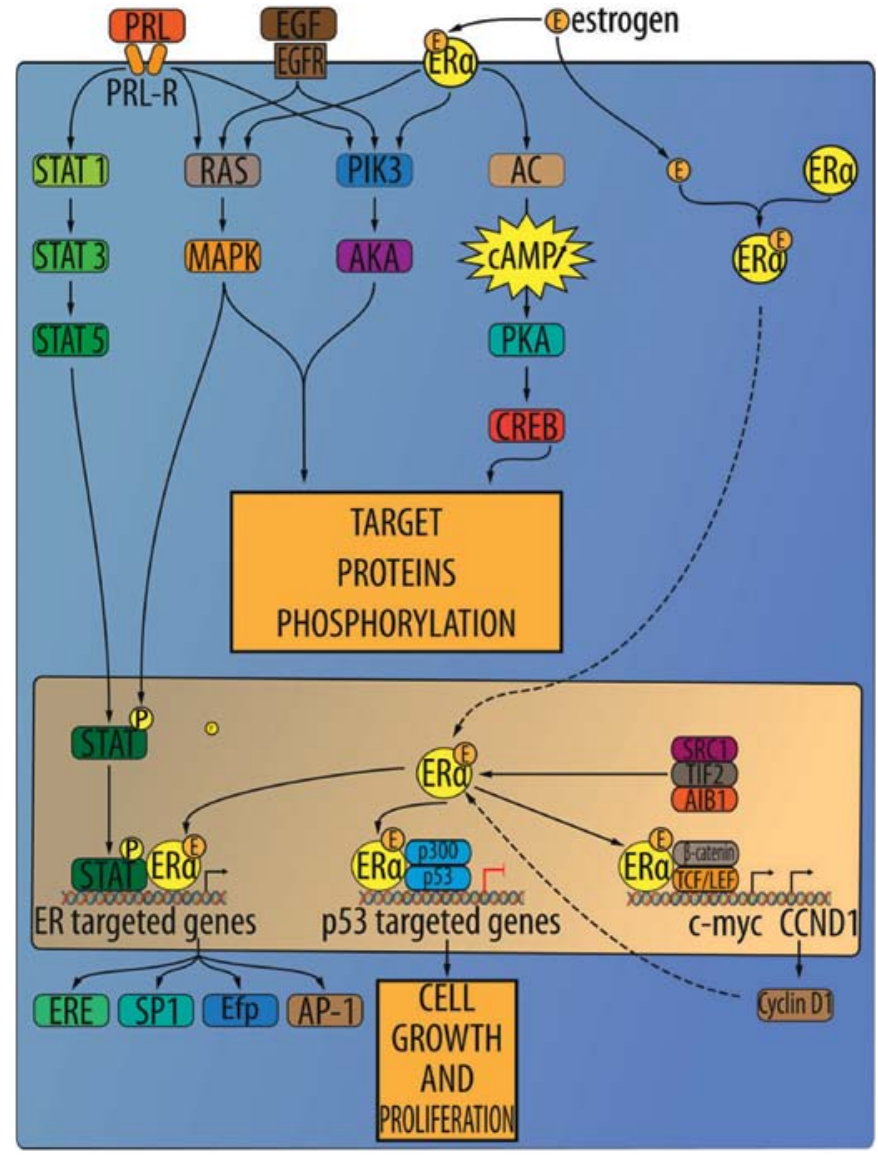

Figure 3. Estrogen and progesterone signaling in RCC cells.

and possibly, xeno-estrogen as well. In normal human kidney and RCC cytosols, both estradiol and progesterone receptors have been found, although a lower binding capacity of human renal cancer cytosols compared to that of normal kidney cytosols was reported, perhaps due to a nuclear translocation of the receptors in the neoplastic tissue (12). Early studies of ER in renal cancer showed that the expression of ERs in RCC was highly variable (85). ERs were detected in only $30 \%$ of the tumors and $40 \%$ of normal kidney tissues, but in some experiments ERs were not detected in any RCC samples. At the same time, ER expression in the interstitial cells of the human kidney, in both adults and children, has also been reported. ER- and PR-positive stroma, described as Müllerian-like, was also found in normal kidneys and metaplastic kidney tissues (86). A recent immunohistochemical study covering 182 RCCs of different subtypes found that ER immunoreactivity was demonstrated in $1.1 \%$ of patients, one with ccRCC, and the other, chromophobe RCC (77). Expression of ER and PR in some human renal tumors has led to suggestions that some of these benign tumor types, particularly mixed epithelial-stromal tumors (MEST), cystic nephromas, or angiomyolipomas with epithelial cysts (AMLEC), may be related to excessive exogenous estrogens. At the same time, the incidence of renal cancer appears to be gender-related, since it is twice as high in men than it is in women. In addition, ER- $\alpha$ genetic polymorphism in the kidneys also seems to play an important role in the development of renal cancer (87). 
Human kidneys were traditionally thought to be unresponsive to estrogen stimulation, but renal tumors as well as angiomyolipomas have been reported to increase in size during pregnancy or as a secondary effect of oral contraceptive therapy. In animal studies, tumors similar to that of human angiomyolipomas have also been observed to grow with estrogen therapy and to regress on tamoxifen. In hamster animal models, renal epithelial tumors have been shown to be inducible with estrogen. Additionally, ovarian-like stromas are reported to be quite common; but on the other hand, they do not constitute the exclusive type of stroma in most tumors of a specific type, and in many tumors no ovarianlike stromas are even present. In early clinical reports, the presence of steroid receptors in renal tissue extracted from nephrectomy specimens was correlated with responses to progesterone-based therapy. In this trial, tumors obtained from 23 patients were examined. In the cytosol fraction of cancer cells, $61 \%$ were found to contain ER and $61 \%$ were found to contain PR. Moreover, $39 \%$ of the tumors tested positive for both ER and PR, while 17\% tested negative for both ER and PR. ER and PR were also examined in the nuclear fraction of 3 renal cancers, and estradiol nuclear receptors were found in 2, while progesterone nuclear receptors were found in 3 . Next, treatment response was evaluated. With few exceptions, patients were treated with the following progestins: medroxyprogesterone acetate (MPA) with R5020, and 17,21-dimethyl-19- norpregna-4,9-diene-3,20-dione, after nephrectomy. The best responders to progestin treatment were those patients with hormone-dependent tumors $\left(\mathrm{ER}^{+}\right.$ $\mathrm{PR}^{-}$or vice versa). These patients did not develop metastases for up to 22 months following nephrectomy. Other patients, also treatment responders, also achieved disease stabilization (SD) with prolonged OS (12). In another study that included primarily perimenopausal female patients (and 1 male patient with a history of diethylstilbestrol treatment after prostatic adenocarcinoma), ER expression in RCC was observed. The excessive growth of RCC in these patients was suggested to be stimulated by therapeutic hormones, overproduction of estrogen, or perimenopausal hormonal abnormalities (88).

Functional cell biology. A novel role for estrogen-induced cathepsin D in hamster kidneys during tumorigenesis that involves renal tubular damage followed by cell proliferation may contribute to renal tumor formation. Primary estrogeninduced RCCs and their metastases showed significantly increased levels of all 3 cathepsin D isoforms. A concomitant increase of cathepsin D, along with estrogen receptor proteins, indicates that cathepsin $\mathrm{D}$ gene expression is under the control of estrogen and is possibly mediated via induced renal estrogen receptors. Cathepsin D is considered to be an early estrogen-response gene. Oncogenes such as c-Myc, c-Fos and c-Jun (and all early estrogen-response genes) are overexpressed in the kidneys after only four months of estrogen treatment. Either tamoxifen or dihydrotestosterone (DHT) prevented the rise in cathepsin D and estrogen receptor content observed after estrogen treatment alone (89). Numerous in vitro studies have suggested the possibility that potentially reactive intermediates of estrogen may be the causative factors contributing to renal cell injury during chronic and prolonged exposure to estrogen $(18,90)$. Estrogen-mediated cytotoxicity were confirmed in various tissues including kidney following chronic estrogen treatment (27).

$E R-\alpha$. Single nucleotide polymorphisms of the ER- $\alpha$ gene in RCC samples were investigated. Six different polymorphic loci of this gene were analyzed in 113 RCCs to determine their frequency. The results showed that the distribution of genotypes of codon 10 varied between RCC patients and healthy controls, and the relative risk of this genotype was calculated as $H R=2.51$. Analysis of DNA from pairs of cancerous and normal tissues detected genotypic changes in $9 \%$ of cancer samples on (and exclusively) exon 1 (codons 10 and 87) of ER- $\alpha$. This leads to the conclusion that codon 10 polymorphism on exon 1 of ER- $\alpha$ may be involved in RCC development. No differences were observed between men and women in the distribution of codon 10 genotypes in the control group. No association was observed between gender, age, or stage of renal cancer with polymorphisms of other genes such as p53 $(91,92)$. Estrogen receptor- $\alpha$ (ER- $\alpha$ ) was recently found to be a novel proteasomal degradation target of the pVHL E3 ligase. Overexpression of VHL suppresses ER- $\alpha$ expression in RCC, whereas downregulation of pVHL can increase ER- $\alpha$ expression (8). Overexpression of ER- $\alpha$ may increase HIF-1 $\alpha$ transcription factor activity. In VHL-deficient cells, the expression of ER- $\alpha$ and HIF- $1 \alpha$ is retained, and blocking ER- $\alpha$ using its inhibitor could suppress the proliferation of VHL-deficient cells as effectively as hypoxia-induced growth suppression. The experiment also showed the anti-proliferative effect of faslodex (ER- $\alpha$ inhibitor) in VHL-deficient cells by inducing p53 expression (8). It was also shown that after binding to ER- $\alpha$, the estrogen complex promotes the transcription of growth-related factors that enhance gene expression and mitosis and promotes proliferation, leading to cancer development and tumor progression (93).

$E R-\beta$. Previous studies indicated that ER- $\beta$ has anti-proliferative and apoptosis-inducing functions (69). In RCC ER- $\beta$ was suggested as tumor suppressor. ER- $\beta$ is highly expressed in RCC cell lines, and estrogen-activated ER- $\beta$ reduced growth hormone downstream signaling activation of the AKT, ERK, $\mathrm{NF}-\kappa \mathrm{B}, \mathrm{MMP} 9$ and JAK signaling pathways but also increased apoptotic cascade activation (caspase-3, -8, -9, BID activation and reduced $\mathrm{Bcl}-2$ and survivin expression). ER- $\beta$ signaling increases RCC cell migration via induction of the VEGFa/ HIF2 $\alpha$ pathway. Moreover, in RCC tumors, infiltrating neutrophils modulate the expression of ER- $\beta$ and in turn promote RCC migration (94). ER- $\beta$ has higher expression in normal renal tissue than in tumorous tissues. In contrast, as no ER- $\alpha$ expression was observed in these cell lines, only ER- $\beta$ was activated through estrogen stimulation. Estrogen treatment significantly decreased the proliferation, migration, invasion, and increased apoptosis of 786-O (high endogenous ER- $\beta$ ), and ER- $\beta$ siRNA-induced silencing attenuated the estrogeninduced effects. Ectopic expression of ER- $\beta$ in A498 (with low endogenous ER- $\beta$ ) increased sensitivity to estrogen. Therefore, estrogen is believed to activate the ER- $\beta$ suppressive function, resulting in the elimination of cancer cells (93) which leads to different RCC incidence rates between males and females. It also implies that ER- $\beta$ may be a useful prognostic marker 
for RCC progression and a novel developmental direction for improved RCC treatment (95).

Treatment. Chronic treatment with diethylstilbestrol (DES) and polydiethylstilbestrol phosphate produced renal tumors in male hamsters. The presence of renal tumors results in increased activity of hepatic glucuronyl transferase that diminishes DES in chronically treated hamsters. The antiestrogen nafoxidine, administered along with DES, completely inhibits tumor formation (96). Ten patients with advanced RCC were given combined chemoendocrine treatment with tegafur and tamoxifen. One out of 2 patients with ER-positive tumors and 3 out of 4 patients with ER-negative tumors responded favorably to this treatment (97).

Androgen receptors $(A R)$. In normal kidneys, androgen receptors (AR) are constitutively expressed in the proximal and distal tubules and localized in cell nuclei. They are also focally expressed in some Bowman's capsule cells. Expression of AR is higher in adjacent normal kidneys than in RCC tissues. AR expression in RCC is negatively correlated with pT stage and Fuhrman's grade (97). In RCC tumors, ARs are detectable in clear cells, papillaries and chromophobe RCCs. No difference of AR immunoreactivity was detected between histological subtypes (77). Upregulated expression of ARs was shown as a favorable marker in RCC $(77,98)$. In another study by Brown et al (99), which included primary clear cell RCCs and their metastases, AR immunoreactivity was mainly present in primary tumors, but not in their respective metastases. AR expression was higher in adjacent normal kidneys (90.9\%) than in RCC tissues or control group human ccRCC cell lines. Specifically, there were $40.7 \%$ AR-positive cases in pT1 compared with $8.0 \%$ in pT3, and $50.0 \%$ of grade I cases were found to be AR-positive compared with $12.9 \%$ in grade III. AR expression was more abundant in primary RCC tissues (12.5\%) than in their respective metastases $(0 \%)$. There was no significant difference found in AR-positive rates between male and female RCC patients from the same subgroups who had the same pT stages or Fuhrman's grades. Immunohistochemical analysis of 182 RCC tumors for $\mathrm{ER}, \mathrm{PR}$, and AR expression in relation to associations with histological subtype, pT stage, grading, gender and impact on disease-free survival was conducted. AR expression was found in 27 of 182 tumors (14.8\%), 24 males and 3 females. AR expression was significantly associated with a lower stage and grade, moderate, or high differentiation of tumor cells. Outcome expectancy decreased with de-differentiation and tumor growth. AR-positive RCCs showed a significantly better prognosis (77). Another study discovered AR to be inversely correlated with TNM stage pT1 tumors being AR-positive for $27 \%$ of cases, in contrast to pT3 tumors being $4 \%$ positive. Additionally, the presence of AR was inversely correlated with nuclear grade. Thus, patients with AR-positive tumors were observed to have a longer progression-free condition and overall survival rate (77). Recently, high AR expression was associated with favorable prognostic factors, such as low pT stage and low histologic Fuhrman's grade among the sample of 120 primary RCCs $(100,101)$. In functional studies androgen receptors (AR) were shown to induce HIF2 $\alpha /$ VEGF signals that potentially drive RCC progression. Anti-AR targeting inhibits RCC cell migration and invasion (102). Normal kidney cells that were transformed into cancerous versions had decreased AR expression rates or more localized cell nuclei. Observations of generally high levels of AR in hamster renal tumors are consistent with the finding that the growth rate of transplanted primary renal tumors is stimulated by testosterone propionate (83). Dihydrotestosterone-specific receptors were present in all RCC samples examined (20 of 20) and in 13 of 14 normal renal parenchyma samples. Testosterone receptors were found in a smaller number of cases. Moreover, significantly higher levels of the dihydrotestosterone receptor were found in high-stage compared to low-stage tumors (103). In summary, the utility of AR in RCC as a prognostic, diagnostic or therapeutic factor is uncertain and requires further investigation and observation.

Treatment. Hormonal manipulation in patients with RCC seems to increase survival in patients with these receptors. The survival rate of patients with 1 or more receptors was significantly higher than that of patients with no receptors (104). Ahmed et al (105) investigated the efficacy of flutamide (an anti-androgenic drug) treatment in Phase II disease-oriented drug trials on patients with advanced bidimensional RCC. Of 25 treated cases, 1 experienced partial cancer remission and 2 were deemed progression-free. Flutamide showed no benefits in patients with disseminated RCC. Sixty-two specimens were evaluated for steroid binding sites: 33 of 62 specimens showed no hormone-binding sites, and only 12 cases exhibited androgen binding.

Progesterone receptors (PR). In normal human kidneys, 30\% of investigated tissue samples were positive for progesterone receptors (PRs) in the mesangial cells of glomeruli, in interstitial stromal cells and in several tubules (86). Two predominant isoforms of PR were found, PR- $\alpha$ and PR- $\beta$, both of which are derived from 1 gene due to alternative promoter usage. Their DNA binding and steroid hormone activities are similar, although higher transcriptional activating potential was observed in the case of PR- $\beta$ (59). The PR was found in $40 \%$ and $30 \%$ of normal and carcinomatous kidney tissue, respectively (105). PR expression was decreased in $10 \%$ of tumors and increased in only $1 \%$ of patients, one with ccRCC and one with pRCC (77). Less frequent than ER, PR was found in stromal cells of benign renal carcinomas: angiomyolipomas, cystic nephromas, oncocytomas, mixed epithelial and stromal tumors, and also in chromophobe RCC (86). Expression of PR in tumor stroma was also reported in benign renal tumors as well as in normal kidneys and metaplastic nodules (86). In general, PR appears to be a highly specific marker for chromophobe RCC. It is also a highly specific and sensitive marker for oncocytomas. In particular, PR immunoreactivity is more abundant in oncocytomas than in chromophobe cancer, which can be used to distinguish between these two tumor types. Moreover, PR expression is not detectable in other subtypes of RCC tumors, such as pRCC or ccRCC with eosinophilic cytoplasm (59).

Treatment. Estradiol receptor (ER) and progesterone receptor (PR) expression was evaluated in $27 \mathrm{RCCs}$ in an attempt to predict the response to progestational therapy. Patients whose 
tumors were positive either for ER or PR (or both) had favorable outcomes from progestational therapy. Three patients with ER-PR-renal cancer showed negative results in followup therapy (12). In the study of McDonald et al (13), PR was measured in eight RCCs compared to nine normal renal tissues and one melanoma tissue sample. PR was identified in all of the samples, with the exception of one RCC. Three patients, all of whom had receptor-positive tumors, were treated with medroxyprogesterone acetate for metastatic disease. In one of these patients, an objective response to treatment was achieved. Nakano et al (104) also demonstrated that hormonal manipulation in patients with one, or more receptors, results in a significantly higher survival rate.

\section{Summary and conclusions}

In the past several decades, clinical observations and molecular studies have led to the hypothesis that RCC is a hormone-dependent tumor. Steroid receptors are transcription factors that control cell differentiation, proliferation and death (12). Active hormone receptors are found to be abnormally expressed in RCC cells, while abnormal endocrine stimulation is thought to influence cell proliferation, migration and angiogenesis. The expression of steroid receptors varies between normal kidney tissues and RCC tumors (59). To date, the study of these receptors in RCC has been confined to estrogen (ER) and progesterone receptors (PR), but the employment of novel molecular biology and cell biology techniques have supplemented the data on steroid hormone RCC dependence. More recently, immunocytochemistry, tissue and protein microarray platforms, mass spectrometry, quantitative reverse real-time PCR, whole genome cDNA analysis, and DNA sequencing have served as functional studies of steroid hormone receptors in renal cancers $(68,106)$. The molecular role of each hormone in RCC pathophysiology is currently still being elucidated, in order to provide a precise model of hormonal interactions with oncogenesis. RCC patients without any paraneoplastic syndromes have experienced frequent changes in peptide hormone balance, which is either directly or indirectly caused by renal cancer tumor masses and which may in turn influence disease biology. On the basis of immunohistochemistry staining, specific hormones can be used as potential biomarkers of progression of oncogenesis, or to aid in the identification of tumor types. Yet, another targeted approach would be to use hormonal receptors for treatment, so as to inhibit hormonal activity with chemical inhibitors. The employment of techniques such as protein and tissue microarray technology, whole genome arrays, mass spectrometry, DNA sequencing, and cell cultures has helped to reveal the expression and role of steroid receptors and their signaling pathways.

Starting with hypothalamus hormones, the presence of the GHRH ligand has been demonstrated in cancer cells, suggesting that GHRH could be a growth factor. In turn, GHRH antagonists exhibit antitumor effects by suppressing the growth of ccRCC lines xenografted into nude mice and inhibiting the growth of orthotopic Caki-1 human RCC, as well as the development of metastases in lung and lymph nodes. The main action of GHRH antagonists in vivo appears to be the direct suppression, through specific binding sites, of auto- crine and/or paracrine production in the pituitary gland and the reduction of expression of the genes encoding IGF-I (IGF1) and IGF-II (IGF2) in tumors. The overexpression of GnRH and its receptor has been found in ccRCC. As LHRH receptor expression was found to be very high in RCCs, its inhibitors can be targeted to ccRCC tumors expressing these receptors for therapy. GnRH antagonists effectively inhibited the growth of tumors in the Caki-1 cell line xenografts of nude mice. As a result, this group of compounds was proposed as a therapy for patients with metastatic or recurrent ccRCC. The role of somatostatin is still unproven and requires further elucidation. On the one hand, in Phase II trials somatostatin analogue administration did not result in the control of RCC growth. However, the findings did raise the possibility of using renalderived somatostatin to modulate tubular cell function through the family of $G$ protein-coupled receptors via autocrine and paracrine modes. It was proposed that the indirect antitumor effects of somatostatin receptors are anti-angiogenic actions. $\mathrm{CRH}$ and Ucn were reported to suppress neovascularization through the reduction of VEGF and the inhibition of tumor cell cycling. POMC was found to be constitutively upregulated in VHL-mutated renal cell carcinoma via Nur77: a critical transcription factor responsible for POMC overproduction that is directly regulated by HIF-1 $\alpha$ during hypoxic conditions.

Biochemical analyses revealed that serum levels of pituitary gland hormones are also significantly modulated in patients with urogenital tumors. Elevated GH and IGF-I levels are associated with oncogenic transformation in a variety of tumors affecting the general population, and induce mitogenic and anti-apoptotic effects; for instance, in RCC, thyroid tumors, and colon cancer, due to local expression of IGF-IR stimulated by excess production in the liver and direct GHR effects in the tumor tissues. These mechanisms can be easily observed in acromegaly patients, who can have multiple cancers simultaneously. ACTH and ACTH receptors are stimulated by the HPA axis in hypoxia, as their production is controlled by the main transcription factor Nur77, the same as in POMC production. Retinoic acid was shown to inhibit Nur77 in the prevention of Cushing's syndrome. TSH and PRL are measured by pathological range in patients with RCC, and are sensitive to indicating distant metastasis in ccRCC carriers. Moreover, hypothyroidism is associated with longer PFS in sunitinib and sorafenib treatments. Prolactin elevation was found in $45 \%$ of ccRCC patients, and its level was unrelated to the stage of the disease. Serum PTH was found to be decreased in patients with tumor dissemination. The FSHR was identified in the tumor endothelium of many genitourinary malignancies, including RCC, in which its expression was mostly observed as being equally located throughout the tumor's neovasculature. According to one hypothesis, FSH signaling could induce VEGF in tumor endothelium, which could contribute to the development of metastatic disease. On the other hand, it makes FSHR an appealing target for therapeutic and imaging purposes and as a prognostic biomarker in genitourinary cancers. FSHR antagonists, such as thiazolidinone analogues, neutralizing antibodies, and negative allosteric modulators should be further examined in clinical trials. GRs are abundantly expressed in ccRCC tumors. Their expression was correlated with a low nuclear grade and tumor stage. High GR expression is considered to 
be a marker of less aggressive RCC tumors. Prolonged OS was reported in RCC patients with GR-positive tumors. GR signaling in RCC cells likely results in the suppression of other transcription factors induced by signaling in cancer cells. MR appears to be a specific and sensitive marker of the distal nephron and its derived carcinomas: chromophobe RCCs and oncocytomas. In the case of ccRCC, MR staining was rarely detected. Therefore, MR serves as a marker for the expression of subtypes of the major types of renal cell neoplasms. In addition, recent studies have also shown that increased activity of the renin-angiotensin-aldosterone system (RAAS), mostly due to hypertension and obesity, is one of the major risk factors influencing genetic changes, and is mostly observed in clear cell forms of RCC. Inhibition of angiotensin-converting enzymes restricts the growth of human renal cancer cells in a mouse xenograft system, and in several experimental animal models of hypertension, overactivity of the RAAS is accompanied by renal tubular hyperplasia. A potential mechanism for this is the influence of isoforms of the K-RAS oncogene, whose overexpression contributes to the survival and increased proliferation of renal cancer cells in response to activation of the RAAS. The expression of VDR is inversely correlated with RCC development risk. The downregulation or loss of receptor expression was only reported in poorly differentiated sarcomatoid tumors with a poor prognosis. However, the amount of the receptor in the receptor-positive tumors did not relate to the other clinical and pathological features of the patients. Vitamin D, depending on dosage, inhibited cancer growth, prolonged overall survival in mice, and reduced hepatic and pulmonary metastates. Because of the vitamin D hypercalcemic toxic effect, alternative vitamin D-like molecules have been explored and have shown promising results; these include alkylating derivatives of $1,25(\mathrm{OH})_{2} \mathrm{D}_{3}$. RAR and RXR are normally expressed in proximal tubules and interstitial cells. RAR- $\beta$ is involved in solid tumorigenesis, as it is associated with the deletion of the short arm of chromosome 3 , where it has been mapped. RAR- $\beta$ mRNA was not detected in renal cancer cell lines, suggesting either resistance to or minimal inhibition with 13-cis-RA treatment. RXR- $\gamma$ was found to be a favorable marker in RCC, with an inverse correlation with clinical and pathological stages. Patients with RXR- $\gamma$-positive tumors were observed to have prolonged OS. Moreover, retinoid treatment with 13-cis-RA resulted in prolonged PFS and OS in RCC patients.

Both ER and PR have been found in cytosols of human RCC, but with a lower binding capacity of cancer cytosols compared to that of normal kidneys, likely due to a nuclear translocation of the receptors in the neoplastic tissue. In clinical studies, positive responses to progestin treatment were demonstrated in patients with hormone-dependent tumors $\left(\mathrm{ER}^{+} \mathrm{PR}^{-}\right.$or vice versa), and in those who either did not develop metastases within 18 to 22 months of nephrectomy or had at least achieved stabilization of the disease and a longer period of survival. The question of the influence of exogenous estrogens is still unclear. First, the expression of ER and PR in some benign human renal tumors has led to suggestions that they may be related to excessive exogenous estrogens, as human kidneys are traditionally thought to be unresponsive to estrogen. Furthermore, angiomyolipomas have been reported to increase in size during pregnancy or secondary oral contraceptive therapy. RCC can be experimentally induced by exposure to estrogens in animal models. Moreover, renal cancer incidence seems to be gender-related, with an incidence that is 2 times higher in men than in women. The data strongly suggest an environmental, exogenous influence of estrogens in RCC etiology, but more research is still needed. The frequency of ER expression in human RCCs was highly variable in different RCC studies. Many reports provide evidence that ER is most often not expressed in RCCs. Moreover, cathepsin D was found to be estrogeninduced in hamster kidneys, leading to tumorigenesis by the mediation of renal tubular damage following reparation of cell proliferation that contributes to RCC formation. In primary estrogen-induced renal tumors and their metastases, significantly elevated levels of all 3 cathepsin D isoforms were detected. ER- $\alpha$ was found to be a novel proteasomal degradation target of the pVHL E3 ligase, thus downregulation of pVHL (in VHL-deficient cells) can increase ER- $\alpha$ expression, which in turn can increase the transcription factor activity of HIF-1 $\alpha$ by binding to it and then promoting tumor progression. Using ER- $\alpha$ inhibitors (i.e. faslodex) could suppress the proliferation of VHL-deficient cells, as could inducing p53 expression. ER- $\beta$ might also play a tumor suppressive, anti-proliferative role. Estrogen-activated ER- $\beta$ reduced growth hormone downstream signaling pathways and also increased apoptotic cascade activation. Estrogen treatment significantly decreased the proliferation, migration, invasion, and increased apoptosis of cell lines with high endogenous ER- $\beta$. Therefore, estrogen is believed to activate ER- $\beta$ 's suppressive function, resulting in the elimination of cancer cells; this could explain different RCC incidence rates between males and females. It is implied that ER- $\beta$ may be a useful prognostic marker for RCC progression and a novel direction for RCC treatment. AR expression was found to be higher in adjacent normal kidneys than in RCC tissues, and was slightly higher in primary RCC tissues than in their respective metastases (no expression). Normal kidney cells that were transformed into cancerous versions had decreased AR expression rates or more localized cell nuclei. They were also negatively associated with pT stage and Fuhrman's grade, although results did not show any significant difference between male and female RCC patients in the subgroups which had the same pT stage or Fuhrman's grade. In contrast, androgen receptor-induced HIF $2 \alpha /$ VEGF signals that drive RCC progression and AR targeting inhibited RCC cell migration and invasion. Additionally, significantly higher levels of the dihydrotestosterone receptor were found in highstage compared to low-stage tumors. PR immunoreactivity serves as a highly specific and sensitive diagnostic marker for chromophobe RCC and oncocytomas, which could be used for distinguishing between these 2 subtypes. PRs are also found in clear cell RCCs, but to a lesser extent. The increased expression of PRs is a favorable prognostic marker in RCC. Prolonged estrogen treatment augments the levels of specific progesterone binding. PRs were found, although less frequently than ER, in mostly ovarian-like stromal cells of benign renal neoplasms. Patients whose tumors were positive either for ER or PR (or both) had favorable outcomes from progestational therapy. The above-mentioned examples underscore the possibility of alternative pathway activation 
in ccRCC via hormones, and demonstrate the need to explore the molecular basis of such phenomena as they are observed in clinics.

\section{Acknowledgements}

The present review was supported by the National Science Centre (NCN) grant no. UMO-2012/05/D/NZ5/01844 and WIM intramural grant $\mathrm{nr} 1 / 8863$ (355).

\section{References}

1. Czarnecka AM, Szczylik C and Rini B: The use of sunitinib in renal cell carcinoma: Where are we now? Expert Rev Anticancer Ther 14: 983-999, 2014.

2. Motzer RJ, Bander NH and Nanus DM: Renal-cell carcinoma. N Engl J Med 335: 865-875, 1996.

3. Wood LS: Renal cell carcinoma: Screening, diagnosis, and prognosis. Clin J Oncol Nurs 13 (Suppl): 3-7, 2009.

4. DeSantis CE, Lin CC, Mariotto AB, Siegel RL, Stein KD, Kramer JL, Alteri R, Robbins AS and Jemal A: Cancer treatment and survivorship statistics, 2014. CA Cancer J Clin 64: 252-271, 2014.

5. Siegel R, Ma J, Zou Z and Jemal A: Cancer statistics, 2014. CA Cancer J Clin 64: 9-29, 2014.

6. Molina AM, Lin X, Korytowsky B, Matczak E, Lechuga MJ, Wiltshire R and Motzer RJ: Sunitinib objective response in metastatic renal cell carcinoma: Analysis of 1059 patients treated on clinical trials. Eur J Cancer 50: 351-358, 2014.

7. Gore ME, Szczylik C, Porta C, Bracarda S, Bjarnason GA, Oudard S, Lee SH, Haanen J, Castellano D, Vrdoljak E, et al Final results from the large sunitinib global expanded-access trial in metastatic renal cell carcinoma. Br J Cancer 113: 12-19, 2015.

8. Jung YS, Lee SJ, Yoon MH, Ha NC and Park BJ: Estrogen receptor $\alpha$ is a novel target of the Von Hippel-Lindau protein and is responsible for the proliferation of VHL-deficient cells under hypoxic conditions. Cell Cycle 11: 4462-4473, 2012.

9. Danilin S, Sourbier C, Thomas L, Rothhut S, Lindner V, Helwig JJ, Jacqmin D, Lang H and Massfelder T: von Hippel-Lindau tumor suppressor gene-dependent mRNA stabilization of the survival factor parathyroid hormone-related protein in human renal cell carcinoma by the RNA-binding protein HuR. Carcinogenesis 30 : 387-396, 2009.

10. Buczek M, Escudier B, Bartnik E, Szczylik C and Czarnecka A: Resistance to tyrosine kinase inhibitors in clear cell renal cell carcinoma: From the patient's bed to molecular mechanisms. Biochim Biophys Acta 1845: 31-41, 2014.

11. Kornakiewicz A, Solarek W, Bielecka ZF, Lian F, Szczylik C and Czarnecka AM: Mammalian target of rapamycin inhibitors resistance mechanisms in clear cell renal cell carcinoma. Curr Signal Transduct Ther 8: 210-218, 2014.

12. Concolino G, Marocchi A, Conti C, Tenaglia R, Di Silverio F and Bracci U: Human renal cell carcinoma as a hormone-dependent tumor. Cancer Res 38: 4340-4344, 1978.

13. McDonald MW, Diokno AC, Seski JC and Menon KM Measurement of progesterone receptor in human renal cell carcinoma and normal renal tissue. J Surg Oncol 22: 164-166, 1983.

14. Concolino G, Di Silverio F, Marocchi A and Bracci U: Renal cancer steroid receptors: Biochemical basis for endocrine therapy. Eur Urol 5: 90-93, 1979.

15. Concolino G, Di Silverio F, Marocchi A and Bracci U: Renal cancer steroid receptors: Biochemical basis for endocrine therapy. Eur Urol 5: 319-322, 1979.

16. Jang JH, Min KJ, Kim S, Park JW and Kwon TK: RU486 induces pro-apoptotic endoplasmic reticulum stress through the induction of CHOP expression by enhancing C/EBPdelta expression in human renal carcinoma Caki cells. J Cell Biochem 117: 361-369, 2015.

17. Zucchetto A, Talamini R, Dal Maso L, Negri E, Polesel J, Ramazzotti V, Montella M, Canzonieri V, Serraino D, La Vecchia C, et al: Reproductive, menstrual, and other hormonerelated factors and risk of renal cell cancer. Int J Cancer 123 2213-2216, 2008

18. Kabat GC, Silvera SA, Miller AB and Rohan TE: A cohort study of reproductive and hormonal factors and renal cell cancer risk in women. Br J Cancer 96: 845-849, 2007.
19. Qu Y, Chen H, Gu W, Gu C, Zhang H, Xu J, Zhu Y and D Age-dependent association between sex and renal cell carcinoma mortality: A population-based analysis. Sci Rep 5: 9160,2015

20. Dunzendorfer U, Drahovsky D and Schmidt-Gayk H: Peptide hormones LH, FSH, TSH, prolactin, beta-HCG and PTH in patients with urogenital tumors. Onkologie 4: 188-192, 1981 (In German).

21. Aguilar-Rojas A and Huerta-Reyes M: Human gonadotropinreleasing hormone receptor-activated cellular functions and signaling pathways in extra-pituitary tissues and cancer cells (Review). Oncol Rep 22: 981-990, 2009.

22. Guillermet-Guibert J, Lahlou H, Cordelier P, Bousquet C, Pyronnet S and Susini C: Physiology of somatostatin receptors. J Endocrinol Invest 28 (Suppl Int): 5-9, 2005.

23. Lu HT, Salamon H and Horuk R: The biology and physiology of somatostatin receptors. Expert Opin Ther Targets 5: 613-623, 2001.

24. Agouni A, Sourbier C, Danilin S, Rothhut S, Lindner V, Jacqmin D, Helwig JJ, Lang H and Massfelder T: Parathyroid hormone-related protein induces cell survival in human renal cell carcinoma through the PI3K Akt pathway: Evidence for a critical role for integrin-linked kinase and nuclear factor kappa B. Carcinogenesis 28: 1893-1901, 2007.

25. Riesenbeck LM, Bierer S, Hoffmeister I, Köpke T, Papavassilis P, Hertle L, Thielen B and Herrmann E: Hypothyroidism correlates with a better prognosis in metastatic renal cancer patients treated with sorafenib or sunitinib. World J Urol 29: 807-813, 2011.

26. Baldazzi V, Tassi R, Lapini A, Santomaggio C, Carini M and Mazzanti R: The impact of sunitinib-induced hypothyroidism on progression-free survival of metastatic renal cancer patients: A prospective single-center study. Urol Oncol 30: 704-710, 2012.

27. Liao H, Zhou Q, Gu Y, Duan T and Feng Y: Luteinizing hormone facilitates angiogenesis in ovarian epithelial tumor cells and metformin inhibits the effect through the mTOR signaling pathway. Oncol Rep 27: 1873-1878, 2012.

28. Schmidinger M, Vogl UM, Bojic M, Lamm W, Heinzl H, Haitel A, Clodi M, Kramer G and Zielinski CC: Hypothyroidism in patients with renal cell carcinoma: Blessing or curse? Cancer 117: 534-544, 2011

29. Dunzendorfer U, Drahovsky D, Schmidt-Gayk H and Zahradnik HP: Clinical significance of peptide hormones LH, FSH, TSH, prolactin, HCG, parathormone, calcitonin and prostaglandin F2 alpha in kidney neoplasms. Z Urol Nephrol 74: 13-19, 1981 (In German).

30. Siraj MA, Pichon C, Radu A and Ghinea N: Endothelial follicle stimulating hormone receptor in primary kidney cancer correlates with subsequent response to sunitinib. J Cell Mol Med 16: 2010-2016, 2012.

31. Schally AV and Varga JL: Antagonistic analogs of growth Hormone-releasing hormone: New potential antitumor agents. Trends Endocrinol Metab 10: 383-391, 1999.

32. Schally AV, Varga JL and Engel JB: Antagonists of growthhormone-releasing hormone: An emerging new therapy for cancer. Nat Clin Pract Endocrinol Metab 4: 33-43, 2008.

33. Jungwirth A, Schally AV, Pinski J, Groot K, Armatis P and Halmos G: Growth hormone-releasing hormone antagonist MZ-4-71 inhibits in vivo proliferation of Caki-I renal adenocarcinoma. Proc Natl Acad Sci USA 94: 5810-5813, 1997.

34. Halmos G, Schally AV, Varga JL, Plonowski A, Rekasi Z and Czompoly T: Human renal cell carcinoma expresses distinct binding sites for growth hormone-releasing hormone. Proc Natl Acad Sci USA 97: 10555-10560, 2000.

35. Rick F, Szalontay L, Abi-Chaker A, Block NL, Halmos G and Schally AV: Effect of novel growth hormone-releasing hormone antagonists on growth of experimental renal cell carcinomas. J Clin Oncol 31: abstr 469, 2013.

36. Vikić-Topić S, Raisch KP, Kvols LK and Vuk-Pavlović S: Expression of somatostatin receptor subtypes in breast carcinoma, carcinoid tumor, and renal cell carcinoma. J Clin Endocrinol Metab 80: 2974-2979, 1995.

37. Turman MA and Apple CA: Human proximal tubular epithelial cells express somatostatin: Regulation by growth factors and cAMP. Am J Physiol 274: F1095-F1101, 1998.

38. Freudenberg LS, Gauler T, Görges R, Bauer S, Stergar H, Antoch G, Bockisch A and Schütte J: Somatostatin receptor scintigraphy in advanced renal cell carcinoma. Results of a phase II-trial of somatostatine analogue therapy in patients with advanced RCC. Nuklearmedizin 47: 127-131, 2008. 
39. Tezval H, Jurk S, Atschekzei F, Becker JU, Jahn O, Serth J and Kuczyk MA: Urocortin and corticotropin-releasing factor receptor 2 in human renal cell carcinoma: Disruption of an endogenous inhibitor of angiogenesis and proliferation. World $\mathrm{J}$ Urol 27: 825-830, 2009.

40. Tezval H, Atschekzei F, Peters I, Waalkes S, Hennenlotter J, Stenzl A, Becker JU, Merseburger AS, Kuczyk MA and Serth J: Reduced mRNA expression level of corticotropin-releasing hormone-binding protein is associated with aggressive human kidney cancer. BMC Cancer 13: 199, 2013.

41. Thwaites DT, Hirst BH and Simmons NL: Passive transepithelial absorption of thyrotropin-releasing hormone (TRH) via a paracellular route in cultured intestinal and renal epithelial cell lines. Pharm Res 10: 674-681, 1993.

42. Arai E, Chiku S, Mori T, Gotoh M, Nakagawa T, Fujimoto H and Kanai Y: Single-CpG-resolution methylome analysis identifies clinicopathologically aggressive $\mathrm{CpG}$ island methylator phenotype clear cell renal cell carcinomas. Carcinogenesis 33: 1487-1493, 2012

43. Keller G, Schally AV, Gaiser T, Nagy A, Baker B, Halmos G and Engel JB: Receptors for luteinizing hormone releasing hormone expressed on human renal cell carcinomas can be used for targeted chemotherapy with cytotoxic luteinizing hormone releasing hormone analogues. Clin Cancer Res 11: 5549-5557, 2005.

44. Engel J, Emons G, Pinski J and Schally AV: AEZS-108: A targeted cytotoxic analog of LHRH for the treatment of cancers positive for LHRH receptors. Expert Opin Investig Drugs 21: 891-899, 2012.

45. Jungwirth A, Schally AV, Halmos G, Groot K, Szepeshazi K, Pinski J and Armatis P: Inhibition of the growth of Caki-I human renal adenocarcinoma in vivo by luteinizing hormone-releasing hormone antagonist Cetrorelix, somatostatin analog RC-160, and bombesin antagonist RC-3940-II. Cancer 82: 909-917, 1998.

46. Choi JW, Park SC, Kang GH, Liu JO and Youn HD: Nur77 activated by hypoxia-inducible factor-1alpha overproduces proopiomelanocortin in von Hippel-Lindau-mutated renal cell carcinoma. Cancer Res 64: 35-39, 2004.

47. Waters MJ: The growth hormone receptor. Growth Horm IGF Res: Jun 7, 2015 doi: 10.1016/j.ghir.2015.06.001 (Epub ahead of print).

48. Gan Y, Buckels A, Liu Y, Zhang Y, Paterson AJ, Jiang J, Zinn KR and Frank SJ: Human GH receptor-IGF-1 receptor interaction: Implications for GH signaling. Mol Endocrinol 28: 1841-1854, 2014.

49. Sekizawa N, Hayakawa E, Tsuchiya K, Yoshimoto T, Akashi T, Fujii T, Yamada S and Hirata Y: Acromegaly associated with multiple tumors. Intern Med 48: 1273-1278, 2009.

50. Asai K, Shimoyama S, Sanno N, Kaminishi M and Oohara T: A rare case of gastric cancer in an acromegalic patient. J Gastroenterol 32: 528-532, 1997.

51. Prinzi N, Sorrenti S, Baldini E, De Vito C, Tuccilli C, Catania A Coccaro C, Bianchini M, Nesca A, Grani G, et al: Association of thyroid diseases with primary extra-thyroidal malignancies in women: Results of a cross-sectional study of 6,386 patients. PLoS One 10: e0122958, 2015.

52. Bailey EB, Tantravahi SK, Poole A, Agarwal AM, Straubhar AM, Batten JA, Patel SB, Wells CE, Stenehjem DD and Agarwal N: Correlation of degree of hypothyroidism with survival outcomes in patients with metastatic renal cell carcinoma receiving vascular endothelial growth factor receptor tyrosine kinase inhibitors. Clin Genitourin Cancer 13: e131-e137, 2015.

53. Nearchou A, Valachis A, Lind P, Akre O and Sandström P: Acquired hypothyroidism as a predictive marker of outcome in patients with metastatic rmenal cell carcinoma treated with tyrosine kinase inhibitors: A literature-based meta-analysis. Clin Genitourin Cancer 13: 280-286, 2015.

54. Siraj A, Desestret V, Antoine M, Fromont G, Huerre M, Sanson M Camparo P, Pichon C, Planeix F, Gonin J, et al: Expression of follicle-stimulating hormone receptor by the vascular endothelium in tumor metastases. BMC Cancer 13: 246, 2013.

55. Radu A, Pichon C, Camparo P, Antoine M, Allory Y, Couvelard A, Fromont G, Hai MT and Ghinea N: Expression of follicle-stimulating hormone receptor in tumor blood vessels. N Engl J Med 363: 1621-1630, 2010.

56. Gartrell BA, Tsao CK and Galsky MD: The follicle-stimulating hormone receptor: A novel target in genitourinary malignancies. Urol Oncol 31: 1403-1407, 2013.
57. Alam H, Weck J, Maizels E, Park Y, Lee EJ, Ashcroft M and Hunzicker-Dunn M: Role of the phosphatidylinositol-3-kinase and extracellular regulated kinase pathways in the induction of hypoxia-inducible factor (HIF)-1 activity and the HIF-1 target vascular endothelial growth factor in ovarian granulosa cells in response to follicle-stimulating hormone. Endocrinology 150: 915-928, 2009.

58. Stanisic TH and Donovan J: Prolactin secreting renal cell carcinoma. J Urol 136: 85-86, 1986.

59. Yakirevich E, Matoso A, Morris D and Resnick M: Steroid receptors in renal cell carcinoma: In: Emerging Research and Treatments in Renal Cell Carcinoma. Ed RJ Amato (ed). InTech, Rijeka, Croatia, 2012.

60. Iwai A, Fujii Y, Kawakami S, Takazawa R, Kageyama Y, Yoshida MA and Kihara K: Down-regulation of vascular endothelial growth factor in renal cell carcinoma cells by glucocorticoids. Mol Cell Endocrinol 226: 11-17, 2004.

61. Yakirevich E, Matoso A, Sabo E, Wang LJ, Tavares R, Meitner P, Morris DJ, Pareek G, Delellis RA and Resnick MB: Expression of the glucocorticoid receptor in renal cell neoplasms: An immunohistochemical and quantitative reverse transcriptase polymerase chain reaction study. Hum Pathol 42: 1684-1692, 2011.

62. Min KJ, Jang JH, Lee JT, Choi KS and Kwon TK: Glucocorticoid receptor antagonist sensitizes TRAIL-induced apoptosis in renal carcinoma cells through up-regulation of DR5 and downregulation of c-FLIP(L) and Bcl-2. J Mol Med Berl 90: 309-319, 2012.

63. Bojar H, Maar K and Staib W: The endocrine background of human renal cell carcinoma. III. Role of inhibitors of R 5020 binding in tumour cytosol. Urol Int 34: 321-329, 1979.

64. Bojar H, Maar K and Staib W: The endocrine background of human renal cell carcinoma. IV. Glucocorticoid receptors as possible mediators of progestogen action. Urol Int 34: 330-338, 1979.

65. Arai Y, Nonomura N, Nakai Y, Nishimura K, Oka D, Shiba M, Nakayama M, Takayama H, Mizutani Y, Miki T, et al: The growth-inhibitory effects of dexamethasone on renal cell carcinoma in vivo and in vitro. Cancer Invest 26: 35-40, 2008.

66. Christophersen AO, Lie AK and Fosså SD: Unexpected 10 years complete remission after cortisone mono-therapy in metastatic renal cell carcinoma. Acta Oncol 45: 226-228, 2006.

67. Yakirevich E, Morris DJ, Tavares R, Meitner PA, Lechpammer M, Noble L, de Rodriguez AF, Gomez-Sanchez CE, Wang LJ, Sabo E, et al: Mineralocorticoid receptor and 11beta-hydroxysteroid dehydrogenase type II expression in renal cell neoplasms: A tissue microarray and quantitative RT-PCR study. Am J Surg Pathol 32: 874-883, 2008.

68. King S, Bray S, Galbraith S, Christie L and Fleming S: Evidence for aldosterone-dependent growth of renal cell carcinoma. Int $\mathrm{J}$ Exp Pathol 95: 244-250, 2014.

69. Varela I, Tarpey P, Raine K, Huang D, Ong CK, Stephens P, Davies H, Jones D, Lin ML, Teague J, et al: Exome sequencing identifies frequent mutation of the SWI/SNF complex gene PBRM1 in renal carcinoma. Nature 469: 539-542, 2011.

70. Kotelevtsev Y, Brown RW, Fleming S, Kenyon C, Edwards CR, Seckl JR and Mullins JJ: Hypertension in mice lacking 11betahydroxysteroid dehydrogenase type 2. J Clin Invest 103: 683-689, 1999.

71. Khan MI, Bielecka ZF, Najm MZ, Bartnik E, Czarnecki JS, Czarnecka AM and Szczylik C: Vitamin D receptor gene polymorphisms in breast and renal cancer: Current state and future approaches (Review). Int J Oncol 44: 349-363, 2014.

72. Nagakura $K$, Hayakawa $M$, Hata $M$ and Nakamura $H$ : 1,25-Dihydroxyvitamin D3 receptors and their relationship to histological features in renal cell carcinoma. J Urol 137: 1300-1303, 1987.

73. Liu W, Tretiakova M, Kong J, Turkyilmaz M, Li YC and Krausz T: Expression of vitamin D3 receptor in kidney tumors. Hum Pathol 37: 1268-1278, 2006.

74. Trydal T, Bakke A, Aksnes L and Aarskog D: 1,25-Dihydro xyvitamin D3 receptor measurement in primary renal cell carcinomas and autologous normal kidney tissue. Cancer Res 48: 2458-2461, 1988.

75. Madej A, Puzianowska-Kuznicka M, Tanski Z, Nauman J and Nauman A: Vitamin D receptor binding to DNA is altered without the change in its expression in human renal clear cell cancer. Nephron Exp Nephrol 93: e150-e157, 2003. 
76. Blomberg Jensen M, Andersen CB, Nielsen JE, Bagi $P$, Jørgensen A, Juul A and Leffers H: Expression of the vitamin D receptor, 25-hydroxylases, 1alpha-hydroxylase and 24-hydroxylase in the human kidney and renal clear cell cancer. J Steroid Biochem Mol Biol 121: 376-382, 2010.

77. Langner C, Ratschek M, Rehak P, Schips L and Zigeuner R: Steroid hormone receptor expression in renal cell carcinoma: An immunohistochemical analysis of 182 tumors. J Urol 171: 611-614, 2004

78. Fujioka T, Hasegawa M, Ishikura K, Matsushita Y, Sato M and Tanji S: Inhibition of tumor growth and angiogenesis by vitamin D3 agents in murine renal cell carcinoma. J Urol 160: 247-251, 1998.

79. Lambert JR, Eddy VJ, Young CD, Persons KS, Sarkar S, Kelly JA, Genova E, Lucia MS, Faller DV and Ray R: A vitamin $\mathrm{D}$ receptor-alkylating derivative of $1 \alpha, 25$-dihydroxyvitamin D3 inhibits growth of human kidney cancer cells and suppresses tumor growth. Cancer Prev Res (Phila) 3: 1596-1607, 2010.

80. Obara W, Konda R, Akasaka S, Nakamura S, Sugawara A and Fujioka T: Prognostic significance of vitamin D receptor and retinoid $\mathrm{X}$ receptor expression in renal cell carcinoma. J Urol 178: 1497-1503, 2007.

81. Motzer RJ, Murphy BA, Bacik J, Schwartz LH, Nanus DM, Mariani T, Loehrer P, Wilding G, Fairclough DL, Cella D, et al: Phase III trial of interferon alfa-2a with or without 13-cisretinoic acid for patients with advanced renal cell carcinoma. J Clin Oncol 18: 2972-2980, 2000.

82. Atzpodien J, Kirchner H, Jonas U, Bergmann L, Schott H, Heynemann H, Fornara P, Loening SA, Roigas J, Müller SC, et al; Prospectively Randomized Trial of the German Cooperative Renal Carcinoma Chemoimmunotherapy Group (DGCIN): Interleukin-2- and interferon alfa-2a-based immunochemotherapy in advanced renal cell carcinoma: A Prospectively Randomized Trial of the German Cooperative Renal Carcinoma Chemoimmunotherapy Group (DGCIN). J Clin Oncol 22: 1188-1194, 2004.

83. Li JJ, Li SA and Cuthbertson TL: Nuclear retention of all steroid hormone receptor classes in the hamster renal carcinoma. Cancer Res 39: 2647-2651, 1979.

84. Vrtačnik P, Ostanek B, Mencej-Bedrač S and Marc J: The many faces of estrogen signaling. Biochem Med Zagreb 24: 329-342, 2014.

85. Hemstreet GP III, Wittliff JL, Sarrif AM, Hall ML III, McRae LJ and Durant JR: Comparison of steroid receptor levels in renalcell carcinoma and autologous normal kidney. Int J Cancer 26 : 769-775, 1980

86. Tickoo SK, Gopalan A, Tu JJ, Harik LR, Al-Ahmadie HA, Fine SW, Olgac S and Reuter VE: Estrogen and progesteronereceptor-positive stroma as a non-tumorous proliferation in kidneys: A possible metaplastic response to obstruction. Mod Pathol 21: 60-65, 2008

87. Fucic A, Gamulin M, Ferencic Z, Katic J, Krayer von Krauss M, Bartonova A and Merlo DF: Environmental exposure to xenoestrogens and oestrogen related cancers: Reproductive system, breast, lung, kidney, pancreas, and brain. Environ Health 11 (Suppl 1): S8, 2012.

88. Adsay NV, Eble JN, Srigley JR, Jones EC and Grignon DJ: Mixed epithelial and stromal tumor of the kidney. Am J Surg Pathol 24 958-970, 2000

89. Li SA, Liao DZ, Yazlovitskaya EM, Pantazis CG and Li JJ: Induction of cathepsin $\mathrm{D}$ protein during estrogen carcinogenesis: Possible role in estrogen-mediated kidney tubular cell damage. Carcinogenesis 18: 1375-1380, 1997.

90. Jakse G and Müller-Holzner E: Hormone receptors in renal cancer: An overview. Semin Surg Oncol 4: 161-164, 1988.
91. Tanaka Y, Sasaki M, Kaneuchi M, Fujimoto S and Dahiya R Estrogen receptor alpha polymorphisms and renal cell carcinoma - a possible risk. Mol Cell Endocrinol 202: 109-116, 2003.

92. Tanaka Y, Sasaki M, Kaneuchi M, Fujimoto S and Dahiya R: Single nucleotide polymorphisms of estrogen receptor alpha in human renal cell carcinoma. Biochem Biophys Res Commun 296: 1200-1206, 2002.

93. Yu CP, Ho JY, Huang YT, Cha TL, Sun GH, Yu DS, Chang FW, Chen SP and Hsu RJ: Estrogen inhibits renal cell carcinoma cell progression through estrogen receptor- $\beta$ activation. PLoS One 8: e56667, 2013.

94. Song W, Yeh CR, He D, Wang Y, Xie H, Pang ST, Chang LS, Li L and Yeh S: Infiltrating neutrophils promote renal cell carcinoma progression via VEGFa/HIF2 $\alpha$ and estrogen receptor $\beta$ signals. Oncotarget 6: 19290-19304, 2015.

95. Ivantsov AO, Imianitov EN, Moiseenko VM, Matsko DE and Artem'eva AS: Expression of Ki-67, p53, bcl-2, estrogen receptors alpha in patients with clear cell renal carcinoma and epidermal growth factor receptor mutation. Arkh Patol 73: 6-7, 2011 (In Russian).

96. Antonio P, Gabaldón M, Lacomba T and Juan A: Effect of the antiestrogen nafoxidine on the occurrence of estrogen-dependent renal tumors in hamster. Horm Metab Res 6: 522-524, 1974.

97. Wada T, Nishiyama K, Maeda M,Hara S, Tanaka N, Yasutomi M and Kurita T: Combined chemoendocrine treatment with tegafur and tamoxifen for advanced renal cell carcinoma. Anticancer Res 15: 1581-1584, 1995.

98. Kimura N, Mizokami A, Oonuma T, Sasano H and Nagura H: Immunocytochemical localization of androgen receptor with polyclonal antibody in paraffin-embedded human tissues. J Histochem Cytochem 41: 671-678, 1993.

99. Brown DF, Dababo MA, Hladik CL, Eagan KP, White CL III and Rushing EJ: Hormone receptor immunoreactivity in hemangioblastomas and clear cell renal cell carcinomas. Mod Pathol 11: 55-59, 1998 .

100. Putz J, Wirth MP, Froehner M and Jahn S: Re: Zhu et al: The expression and evaluation of androgen receptor in human renal cell carcinoma (Urology 2014;83:510.e19-24). Urology 84: 734-735, 2014

101. Zhu G, Liang L, Li L, Dang Q, Song W, Yeh S, He D and ChangC: The expression and evaluation of androgen receptor in human renal cell carcinoma. Urology 83: 510.e519-524, 2014.

102. He D, Li L, Zhu G, Liang L, Guan Z, Chang L, Chen Y, Yeh S and Chang C: ASC-J9 suppresses renal cell carcinoma progression by targeting an androgen receptor-dependent HIF $2 \alpha /$ VEGF signaling pathway. Cancer Res 74: 4420-4430, 2014.

103. Noronha RF and Rao BR: Increased dihydrotestosterone receptor levels in high-stage renal adenocarcinoma. Cancer 56 : 134-137, 1985

104. Nakano E, Tada Y, Fujioka H, Matsuda M, Osafune M, Kotake T, Sato B, Takaha M and Sonoda T: Hormone receptor in renal cell carcinoma and correlation with clinical response to endocrine therapy. J Urol 132: 240-245, 1984.

105. Ahmed T, Benedetto P, Yagoda A, Watson RC, Scher HI, Herr HW, Sogani PC, Whitmore WF and Pertschuk L: Estrogen, progesterone, and androgen-binding sites in renal cell carcinoma. Observations obtained in Phase II trial of flutamide. Cancer 54: 477-481, 1984.

106. Liu Z, Lu Y, He Z, Chen L and Lu Y: Expression analysis of the estrogen receptor target genes in renal cell carcinoma. Mol Med Rep 11: 75-82, 2015. 